\title{
Local Cellular Responses to Metallic and Ceramic Nanoparticles from Orthopedic Joint Arthroplasty Implants
}

This article was published in the following Dove Press journal: International Journal of Nanomedicine

\section{Li Zhang \\ El-Mustapha Haddouti \\ Kristian Welle \\ Christof Burger \\ Koroush Kabir iD* \\ Frank A Schildberg $\mathbb{D D}^{*}$ \\ Clinic for Orthopedics and Trauma Surgery, University Hospital Bonn, Venusberg-Campus I, Bonn 53I27, Germany \\ *These authors contributed equally to this work}

Correspondence: Koroush Kabir; Frank A Schildberg

Email koroush.kabir@ukbonn.de;

frank.schildberg@ukbonn.de

\begin{abstract}
Over the last decades, joint arthroplasty has become a successful treatment for joint disease. Nowadays, with a growing demand and increasingly younger and active patients accepting these approaches, orthopedic surgeons are seeking implants with improved mechanical behavior and longer life span. However, aseptic loosening as a result of wear debris from implants is considered to be the main cause of long-term implant failure. Previous studies have neatly illustrated the role of micrometric wear particles in the pathological mechanisms underlying aseptic loosening. Recent osteoimmunologic insights into aseptic loosening highlight the important and heretofore underrepresented contribution of nanometric orthopedic wear particles. The present review updates the characteristics of metallic and ceramic nanoparticles generated after prosthesis implantation and summarizes the current understanding of their hazardous effects on peri-prosthetic cells.
\end{abstract}

Keywords: nanoparticles, joint arthroplasty, osteoblasts, osteoclasts, macrophages, mesenchymal stem cells

\section{Introduction}

Over the last decades, total joint arthroplasty (TJA), such as knee, hip, ankle, elbow and others, has become the most successful procedure in treating joint diseases. Though TJAs provide pain relief and function restoration with minimal impact of activities of daily life, their long-term prosthesis survival still remain a concern. Osteolysis is the most common long-term complication after total joint replacement surgery. ${ }^{1}$ Aseptic implant loosening secondary to periprosthetic osteolysis is the leading cause of revision procedures for elbow, hip, knee, or ankle TJA and is the predominant limiting factor of the longevity of current TJAs prosthesis. ${ }^{2-6}$ As the only established treatment for peri-prosthetic osteolysis to date, revision surgery is technically complex, and is associated with a high rate of complications, high morbidity rate, poor clinical and functional performance, as well as significant economic impact on the healthcare system. ${ }^{7}$

The particulate wear particles of different material types of prostheses have been recognized as one of the major factors responsible for aseptic implant loosening after joint arthroplasty. ${ }^{8}$ Metals, ceramics, and polymers are the commonly used orthopedic biomaterials. After implantation, these prostheses become an internal source of wear particles upon corrosion and abrasion. ${ }^{9-12}$ Once released, wear particles can infiltrate into the systemic circulation causing systemic toxicity. ${ }^{13,14}$ 
They also locally accumulate in adjacent tissue and space, such as bone and bone marrow. ${ }^{15}$ Thereafter, these nondegradable particles can represent a long-term hazard and principally interact with the complex peri-implant cell lineages such as bone-forming osteoblasts and their progenitors, bone marrow residing mesenchymal stem cells (MSCs), macrophages, osteoclasts and fibroblasts. This process induces adverse cellular effects and contributes to the pathological mechanisms underlying implant aseptic loosening.

Particulate wear debris range in size from micron to sub-micron. Nanoparticles (NPs) are defined as ultrafine particles with external dimensions with a size of 1-100 $\mathrm{nm}$. Compared to their micro-sized counterparts, nano-sized particles are more biologically active to periimplant cells. They induce greater cytotoxicity, inflammation, cytokine release, more free radical production and chromosomal damage. ${ }^{16}$ However, difficulties in isolating and characterizing nano-scale particles until today suggest that the number and adverse effect of NPs might have been underestimated. ${ }^{17}$ Given these challenges, an in-depth understanding of local cellular responses to the released nanoscale wear debris from orthopedic implants will provide a new area in the comprehension of aseptic loosening and offers new scientifically based recommendations to better design suitable prosthetic interfaces and scaffolds. Therefore, in the present review, we provide a general overview of the characteristics of nano-sized metallic and ceramic orthopedic implant wear particles and highlight their biological effect on peri-implant cells. Finally, future challenges in transferring preclinical knowledge to clinical practice are discussed.

\section{Peri-Implant Cell Lineages}

After their release, wear particles interact with a complex and diverse collection of cell types in peri-implant tissue adjacent to joint prostheses. Cellular responses to wear particles contribute to pathological mechanisms underlying aseptic loosening because they help determine the rate of occurrence of implant osteolysis at mid-term and longterm implantation time. Here, we mainly focus on 4 cell lineages: macrophages, osteoblasts, osteoclasts, and MSCs.

\section{Macrophages}

Macrophages are the key cells in the response to wear particles from joint arthroplasty. ${ }^{18,19}$ During the progression of osteolysis, they are systemically recruited to the local site of particle generation. Notably, in osteal tissues also resident osteal tissue macrophages (OsteoMacs) are present,${ }^{20}$ however, their contribution to aseptic loosening has never been studied and needs further exploration. As sentinels of the innate immune system, macrophages are the first cell types involved in this response by recognizing, internalizing, and getting activated upon wear particle exposure. Previous studies reported that nanoscale wear particles induced an increased M1/M2 (pro-inflammatory phenotype/anti-inflammatory phenotype) macrophage ratio in vitro and in vivo. ${ }^{21}$ Once activated, macrophages initiate inflammatory cascades characterized by the release of pro-inflammatory cytokines, such as IL-1 $\beta, \mathrm{TNF} \alpha$, and IL-6. These reactions create an inflammatory microenvironment that facilitates osteoclast activation, bone destruction, and eventually aseptic loosening. ${ }^{19,21}$

\section{Osteoblasts}

Osteoblasts are the main bone-forming cells responsible for bone deposition and implant osseointegration. They synthesize the components of bone matrix, regulate their mineralization and modulate osteoclasts. Responsible for extracellular matrix expression, their cytoplasm is rich in organelles necessary for protein secretion such as welldeveloped rough endoplasmic reticulum, large Golgi complex, transfer vesicles, secretory granules, and electron-dense mitochondria. They synthesize the majority of bone matrix constituents including osteocalcin, alkaline phosphatase (ALP) and a large amount of type I collagen and regulate their mineralization. In addition, their cytoskeleton is responsible for cellular structural and mechanical properties such as elasticity and spring constant, ${ }^{22}$ which is important to establish successful implant integration. ${ }^{23}$ By this, osteoblasts provide a foundation upon which the new bone tissue can grow and thus play a leading role in postoperative implant osseointegration which is crucial for early fixation as well as long-term success of orthopedic implants. Importantly, osteoblasts interact with osteoclasts in a delicate balance via secreted factors such as receptor activator of nuclear factor (NF)$\kappa \mathrm{B}$ ligand (RANKL) and osteoprotegerin (OPG). Binding of RANKL to RANK activates NF- $\kappa B$ signaling pathway that ultimately leads to osteoclastogenesis. OPG is a soluble "decoy receptor" for RANKL and thus a physiological negative regulator of osteoclastogenesis.

Osteoblasts are rather responsible for bone formation. In the context of wear particles, they also indirectly participate in bone degeneration by demonstrating direct 
cellular dysfunction (eg, reduced viability, differentiation and mineralization), changing expression of specific inflammatory cytokines (eg, TNF $\alpha$, IL-1 $\beta$, IL-6, and $\mathrm{M}-\mathrm{CSF}$ ) as well as directly by the secretion of preosteolytic mediators and specific proteinases. ${ }^{24,25}$ These factors not only impair osteoblastic bone formation but also exacerbate osteoclastic bone resorption, which ultimately lead to peri-implant osteolysis.

\section{Osteoclasts}

Osteoclasts are the only in vivo cells with bone resorption function. They derive from bone marrow monocyte/ macrophage lineage cells. Osteoclastic bone resorption consists of a two-phase process. Bone is acid demineralized, followed by degradation of the demineralized type I collagen-rich matrix by secreted cathepsin $\mathrm{K}$ and other acidic proteinases. Osteoclasts maintain bone metabolism homeostasis by acting synergistically with osteoblasts. Numerous hormones, growth factors, and cytokines modulate osteoclast activity by regulating their differentiation, activation, life span, and function. For example, the RANKL/OPG expression ratio determines the degree of osteoclast differentiation and function, and has been shown to be implicated in the process of osteolysis. M-CSF binds to c-FSM and promotes osteoclast proliferation and osteoclast precursor survival. RANKL stimulates RANK on the osteoclast precursor's surface and activates NF- $\kappa \mathrm{B}$ signaling pathways. Activated NF- $\kappa \mathrm{B}$ favors the survival, differentiation, and activation of osteoclasts through the nuclear factor of activated $\mathrm{T}$ cells cytoplasmic 1 (NFATc1). ${ }^{26}$

Unfortunately, to date, only a small number of studies about the direct interaction between osteoclasts and wear particles have been published. Osteoclasts have also been shown to be capable of phagocytosing wear particles in vitro. $^{27,28}$ Nevertheless, after being fully differentiated in vitro, osteoclasts lose the ability to release inflammatory cytokines, ${ }^{29}$ indicating a diminished role of osteoclasts in potentiating implant debris-induced inflammation and osteolysis.

\section{MSCs}

Multipotent MSCs are residing in bone marrow, trabecular bone, the walls of the microvasculature, and adjacent to implants. By their differentiation into osteoblasts and regulating osteoclast differentiation and activation, MSCs play a critical role in maintaining implants' osseointegration and interface stability, which might determine the rate of occurrence of osteolysis at mid-term and long-term implantation time.

MSCs have been implicated as a target of particles during aseptic loosening. ${ }^{30}$ They have been shown to internalize NPs via endocytosis. ${ }^{31,32}$ Accumulating evidence indicates that, upon exposure to micron- and submicronsized particles, MSCs demonstrated ultrastructural changes and compromised cellular functions such as viability, proliferation, migration, ${ }^{33,34}$ osteogenic differentiation, and subsequent bone formation as well as disbalanced RANKL/OPG secretion. ${ }^{30,35-38}$ These cellular reactions decrease new bone formation, exacerbate osteoclastic bone resorption at the bone-implant interface and contribute to implant loosening.

\section{Metal NPs}

Metal implants have been used for biomedical applications since the 19th century. Within the past two decades, they have evolved into the most widely used material in the orthopedic field, eg, fracture repair, joint arthroplasty, due to their high mechanical resistance, excellent molding characteristics and biological compatibility, whereas the long-term effects of wear debris are not known completely. To date, the majority of metal implants are based on titanium (Ti), cobalt (Co) and chromium (Cr). ${ }^{39,40}$ Moreover, Tantalum (Ta) components are receiving increasing interest as load-bearing orthopedic biomaterial because of their outstanding biocompatibility, corrosion resistance, and superior strength. ${ }^{41,42}$ In order to improve their tribological performance as well as their osseointegration, a number of different surface modification techniques have been recently applied. However, when mechanical stress overwhelms components' protective capacity, corrosive substances such as metallic particles, inorganic metallic salts as well as free metal ions are released. ${ }^{43}$ These products, mostly released from metal-on -metal (MOM) and metal-on-polyethylene (MOP) bearings, can accumulate in the surrounding tissues, or even disseminate to distant lymph nodes and organs, ${ }^{44-46}$ causing adverse local and/or systemic risk.

\section{Ti- and $\mathrm{TiO}_{2}$-Based NPs}

Ti and Ti-based alloys (eg, Ti-6Al-4V) have evolved to be the most used orthopedic implant materials due to their advantageous bulk mechanical properties and biocompatibility compared to other metallic biomaterials. ${ }^{47}$ However, the main limitation of them is their poor tribological behavior. ${ }^{48}$ Notably, Ti alloys can naturally form a passive protective 
titanium dioxide $\left(\mathrm{TiO}_{2}\right)$ layer which provides them with an excellent biocompatibility and corrosion resistance. Therefore, in vivo corrosion and wear of Ti-based implants can produce both $\mathrm{Ti}$ and $\mathrm{TiO}_{2}$ particles (commonly rutile and anatase). ${ }^{49,50}$ Interestingly, as $\mathrm{TiO}_{2}$ NPs have been widely applied in the food industry (packaging and food additives) as well as cosmetic products (eg, toothpaste and sun cream) and are consumed by millions of people on a daily basis, ${ }^{51}$ attention has already been drawn due to its potential adverse effects through oral and inhalation exposure. ${ }^{52-57}$ Yet, the potential effect of $\mathrm{TiO}_{2}$ NPs on skeletal system as nanobiomedical applications when exposed internally has not been fully understood.

\section{Effects of Ti NPs on Macrophages}

Recent studies showed that Ti NPs (52 nm) drove RAW 264.7 cells to polarize into the M1 phenotype (proinflammatory phenotype) and increased inflammatory cytokine (TNF $\alpha$, IL-6) production. ${ }^{58} \mathrm{LiCl}$ promoted M2 macrophage polarization, reduced pro-inflammatory cytokines and enhanced the release of anti-inflammatory and bonerelated cytokines, such as IL-4, IL-10 and bone morphogenetic protein 2 (BMP-2) and vascular endothelial growth factor (VEGF). This effect may be attributed to LiCl's attenuation on $\mathrm{Ti}$ nanoparticle-induced activation of ERK and p38 phosphorylation in vitro. Further, in vivo results from an experimental air pouch model confirmed LiCl's protective effect on Ti nanoparticle-mediated inflammatory reaction through regulating the ratio of $\mathrm{M} 1 / \mathrm{M} 2$ macrophages. ${ }^{58}$ Furthermore, recent studies showed that in vitro TiAl6V4 and CoCrMo nanoparticle-induced inflammatory responses in RAW 264.7 cells were mediated by the

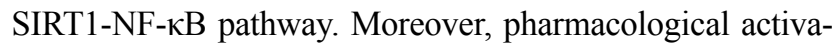
tion of SIRT1 by resveratrol attenuated osteolysis and local inflammatory responses in these two metal particle-induced osteolysis (PIO) mouse models. ${ }^{59}$ The above-mentioned results indicated that Ti NPs can drive macrophage polarization and induce inflammation both in vitro and in vivo. $\mathrm{LiCl}$ and resveratrol can mitigate particle-induced osteolysis through attenuating these effects.

\section{Effects of Ti NPs on Osteoblasts and MSCs}

Despite the excellent biocompatibility characteristics of $\mathrm{Ti}$ in bulk form, the adverse effects of Ti particles on osteoblast functions have been characterized by a number of researchers. ${ }^{60-63}$ Pure Ti particles have been reported to induce apoptosis in osteoblasts. ${ }^{64,65}$ In accordance to this, nano-sized Ti NPs (30 nm) dose- and time-dependently induced apoptosis in Saos-2 human osteoblast-like cells. Furthermore, increased elasticity and spring constant and decreased osteoblastic mineralization ability were observed. ${ }^{66}$ Notably, Ti NPs induced a less pronounced effect than Co NPs, ${ }^{66}$ possibly as a result of Ti NPs' lower uptake rate and better cytocompatibility. The same group also compared Ti with Co NPs on MC3T3E1 cells in vitro. Similarly, although a general decline in viability was found after a Ti $(30 \mathrm{~nm}) \mathrm{NP}$ exposure for 72 hours, there was no significant change in cell elasticity, spring constant, adhesion forces as well as osteoblastic mineralization ability after 21 days, ${ }^{67}$ probably due to less particle concentration applied compared to previous studies. Not surprisingly, Ti still induced less increase in spring constant than same sized Co NPs.

Osteogenic inhibition and bone destruction have been observed in Ti particle-induced mouse models. GSK-3 $\beta$ / $\mathrm{Wnt} / \beta$-catenin signaling pathway has been reported as a key mediator of this process both in vitro and in vivo. Inhibiting GSK-3 $\beta$ activity with drugs such as melatonin, icariin, ghrelin, and $\mathrm{LiCl}$ increased downstream $\beta$-catenin expression, and mitigated Ti particle-induced suppression of osteogenesis, both in vitro and in vivo. ${ }^{68-72}$ Unfortunately, to date, the involvement of GSK-3 $\beta / \mathrm{Wnt} / \beta$-catenin signaling pathway in nano-sized Ti particle-induced osteolysis has never been studied. More studies are needed to elucidate this aspect.

Nano-sized Ti alloy particles $(90 \%$ with a diameter of less than $100 \mathrm{~nm}$ ) caused morphology changes, inhibited rabbit BMSC proliferation, and enhanced the apoptosis rate in vitro in a dose- and time-dependent manner. ${ }^{37}$ Moreover, Preedy et al reported rat MSCs exposed to increasing concentrations of $\mathrm{Ti}$ NPs $(30 \mathrm{~nm})$ resulted in a lower cell elasticity. ${ }^{38}$ Notably, Ti NPs induced less effect than Co NPs with similar diameter, supporting the cytocompatibility of the former. Unfortunately, previous studies mainly focused on MSC's physiological function change on Ti implant surface with different nanoparticle coating, ${ }^{73,74}$ and no studies are available addressing the effect of nano-sized Ti particles on MSCs. Only one study reported that rat BMSCs demonstrated reduced osteogenic differentiation after incubation with supernatant from Ti NP-stimulated RAW264.7 cells, indicating Ti NP's indirect influence on BMSCs via macrophage-MSC communication. Thus, more studies are needed in the future. ${ }^{58}$

\section{Effects of $\mathrm{TiO}_{2}$ NPs on Macrophages}

Until now, although $\mathrm{TiO}_{2}$ NPs have been investigated in different cell lines, the underlying mechanisms of how 
macrophages internalize $\mathrm{TiO}_{2}$ NPs have not been fully understood. Recently, Chen et al firstly reported that $\mathrm{TiO}_{2}$ NPs were probably endocytosed using proteomic analysis in mouse bone marrow-derived macrophages (BMDMs). ${ }^{75}$ Also, they found that $\mathrm{TiO}_{2}$ NPs decreased mitochondrial function, elicited inflammatory responses through activating COX-2 pathways. Notably, an attenuated phagocytic capability of macrophages was observed upon in vitro $\mathrm{TiO}_{2} \mathrm{NP}$ exposure, suggesting potential detrimental effects on immune responses. This result is consistent with results from Huang et al. They found that $\mathrm{TiO}_{2}$ NPs can prime a specific state of murine macrophages characterized by excessive inflammation (increased pro-inflammatory genes and decreased antiinflammatory genes) and suppress innate immune function both in vitro and in vivo in a TLR4-dependent manner. ${ }^{76}$ These results suggest that $\mathrm{TiO}_{2}$ NPs drive macrophage polarization and impair macrophage's immune response and may enhance the susceptibility to bacterial infection upon long-time exposure.

ROS-dependent signaling plays a key role in the macrophage- $\mathrm{TiO}_{2} \mathrm{NP}$ interaction. The cytotoxic ability induced by $\mathrm{TiO}_{2}$ NPs was dependent on ROS. ${ }^{77}$ Recently, Dhupal et al reported that $\mathrm{TiO}_{2}$ NPs (20 nm, negative charge) induced immunotoxicity (apoptosis and toll-like receptor activation) in murine RAW 264.7 cells through ROS-dependent SAPK/ JNK and p38 MAPK activation pathway. ${ }^{78}$

$\mathrm{TiO}_{2}$ NPs have also been reported to activate the NLRP3 inflammasome in macrophages. ${ }^{57,79}$ This process, which releases pro-inflammatory IL-1 $\beta$ and IL-18, induces pyroptosis and contributes to its inflammatory and cytotoxic effect. Morishige et al challenged THP-1-derived macrophages with $\mathrm{TiO}_{2}$ anatase and rutile NPs and found that macrophages recognized and phagocytosed $\mathrm{TiO}_{2}$. Further, $\mathrm{TiO}_{2}$ NPs induced NALP3 inflammasome activation and IL-1 $\beta$ release in a ROS- and cathepsin B-dependent manner. ${ }^{80}$ Recently, Baron reported that nano- $\mathrm{SiO}_{2}$ and nano- $\mathrm{TiO}_{2}$ triggered ATP release, which is a known ROS inducer, and resulted in subsequent NLRP3 inflammasome formation in macrophages through the activation of PLC-InsP3 and inhibition of ADCY-cAMP pathways. ${ }^{79}$

Different $\mathrm{TiO}_{2}$ NP structures may result in diverse biological reactions in macrophages. Recently, Yu suggested that $\mathrm{TiO}_{2}$ rutile NPs cause more severe lysosomal membrane permeabilization (LMP) than anatase NPs in RAW264.7 cells. $\mathrm{TiO}_{2}$ anatase caused less severe necrosis and LMP than rutile NPs, but more severe mitochondrial dysfunction associated with higher levels of apoptosis. ${ }^{81}$

\section{Effects of $\mathrm{TiO}_{2}$ NPs on Osteoblasts and MSCs}

Although they are thought to be nonphagocytic cells, osteoblasts have been shown to engulf and internalize particulate debris within the osteoblast cytoplasm. Cai et al reported that OBs take up $\mathrm{TiO}_{2}$ NPs mainly via clathrin-mediated and

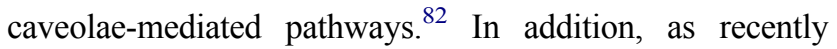
described, $\mathrm{TiO}_{2}$ anatase NPs form bio-complexes with proteins and ions from cell culture medium, which act as a kind of "Trojan-horse" internalization by primary human osteoblasts. ${ }^{83}$ Nano-TiO $_{2}$ particles (4 and $40 \mathrm{~nm}$ ) disrupt the cytoskeletal networks and impair migration in Saos-2 cells. They also increased FAK phosphorylation and reduced vinculin expression (using $5 \mathrm{~nm}$ NPs), resulting in impaired cell adhesion. ${ }^{84}$ Interestingly, these cellular reactions were size-dependent, with NPs smaller than $5 \mathrm{~nm}$ having a stronger impact than $40 \mathrm{~nm}$ NPs. Also, after NP internalization, evidence of extensive DNA fragments, autophagolysosome-like structures, ultrastructure organelle damage (eg, mitochondria swollen), and intensive vacuolization was identified, suggesting cell damage and necrotic lysis. ${ }^{83,85}$ Accordingly, a dose- and time-dependent cytotoxicity on human ${ }^{83-85}$ and rodent ${ }^{86-88}$ osteoblasts was observed. This could be attributed to increased oxidizing stress after NP exposure. ${ }^{85}$ Additionally, decreased ALP activity and increased RANKL expression and MMP-9 activity were also observed, suggesting decreased osteogenic differentiation and osteoclastogenesis. ${ }^{85,86}$ The inflammatory response of osteoblasts to $\mathrm{TiO}_{2}$ NPs was evaluated in a 3D Saos-2 spheroid. Cytokines (IL-1 $\beta$, IL-6, IL-8, IL-12, IL-15, IL-4, IL-10), chemokines (Rantes, MIP-1, IP-10), and VEGF secretion were increased in the supernatant, ${ }^{89}$ which is of particular interest as some of these molecules are involved in osteolysis and bone homeostasis. In summary, after internalization by $\mathrm{OBs}, \mathrm{TiO}_{2}$ NPs hamper osteoblastic cellular function (eg, viability, osteogenic differentiation), promote inflammation, and thus contribute to peri-implant osteolysis.

In terms of MSCs, Hou et al reported that, after internalization, $\mathrm{TiO}_{2}$ NPs of different sizes $(14 \mathrm{~nm}, 108 \mathrm{~nm}$, and $196 \mathrm{~nm}$ ) had adverse effects on cell viability, proliferation, adhesion and migration on rat bone marrowderived MSCs, in a dose- and size-dependent manner. Also, osteogenic differentiation was suppressed, characterized by less osteocalcin (OCN) and osteopontin (OPN) expression, weaker ALP activity, and mineralization ability. ${ }^{82}$ Interestingly, bigger (196 nm) NPs demonstrated stronger adverse effects than smaller (14 nm and $108 \mathrm{~nm}$ ) ones, possibly due to higher accumulation of bigger NPs 
within MSCs. Similarly, Hackenberg et al also reported a significant reduction in migration of $\mathrm{TiO}_{2}$ NP-treated human MSCs after 3 weeks without affecting their multidifferentiation capacity. ${ }^{34}$

\section{$\mathrm{Co} / \mathrm{Cr} \mathrm{NPs}$}

Humans are exposed to $\mathrm{Co}$ and $\mathrm{Cr}$ from industry and surgical devices. ${ }^{14}$ MOM replacements were introduced as an alternative bearing surface to MOP in arthroplasty because of their excellent wear and corrosion resistance. ${ }^{90}$ The bulk CoCrMo alloys are composed of 58.9-69.5\% Co, 27.0-30\% $\mathrm{Cr}, 5.0-7.0 \%$ Mo as well as a small amount of elements such as (Mn, Si, Ni, Fe, and $\mathrm{C}$ ) to improve physical properties. ${ }^{91}$ In synovia, they spontaneously form a passive oxide layer which enhances the chemical and mechanical stability. This stable surface layer (up to $85 \mathrm{~nm}$ in thickness) is primarily composed of $\mathrm{Cr}(90 \%)$ in the form of oxides, phosphates, and hydroxides as well as minimal Co (5\%) in the form of $\mathrm{CoO}, \mathrm{Co}(\mathrm{OH})_{2}$, and $\mathrm{Co}$ phosphate. However, MOM implants are not immune to corrosion and wear. They have been reported to generate metal particles as well as ions in vivo. ${ }^{91,92}$ Wear particles obtained from periprosthetic tissues of MOM patients were reported to be at the nanometer scale (smaller than $50 \mathrm{~nm}$ ) with morphologies being oval, round, needle-shaped. ${ }^{93-96}$ The majority of found wear debris were comprised of oxidized $\mathrm{Cr}$ (III) particles with minimal or no Co (IV), which correlate well with the surface composition of $\mathrm{CoCr}$ alloy. This can cause adverse reactions, such as the generation of pseudotumors, extensive necrosis, early osteolysis, and implant failure. Though metal ions released from $\mathrm{CoCr}$ nanoparticle surfaces can also trigger additional toxicity in cells; ${ }^{97}$ however, this is not our focus and will not be discussed here.

\section{Effects of Co/Cr NPs on Macrophages}

Similar to histological results from Co nanoparticle-induced lung injury, ${ }^{98,99}$ assessments of retrieved tissues from patients with failed $\mathrm{CoCr}$ alloy hip prostheses demonstrated necrosis, as well as macrophagic and lymphocytic infiltrates. ${ }^{95-97}$ This suggests cytotoxicity of wear products and macrophagic recruitment in periprosthetic tissue.

Kwon reported that Co NPs (30-60 nm) and ions demonstrated dose-dependent cytotoxic effects on the RAW 264.7 murine macrophage cell line in vitro. ${ }^{100}$ This is in accordance with the result by Liu et al. ${ }^{101}$ Notably, Ti and Cr NPs did not result in a significant viability reduction under the same condition. Wang et al suggest that Co NP's cytotoxicity on RAW 264.7 cell could be attributed to Co ions released due to corrosion in the lysosomes. Interestingly, changing the acidic environment inside the lysosome using Bafilomycin A1 protects the viability of RAW264.7 cells and suppresses Co NPinduced aseptic inflammation by inhibiting intracellular $\mathrm{Co}$ NP corrosion and Co ions release. ${ }^{102}$ The cytotoxic and inflammatory effects of Co NPs $(28 \mathrm{~nm})$ on macrophages were also observed by Nyga et al. This effect is dependent on hypoxia-inducible factor (HIF), a ROS-independent pathway. ${ }^{103}$ Notably, it is Co NPs, but not Cr NPs, which inhibit macrophage migration both in vitro and in vivo by promoting adhesion at non-cytotoxic concentrations; this is associated with ROS-RhoA signaling pathway. ${ }^{104}$

\section{Effects of Co/Cr NPs on Osteoblasts and MSCs}

Upon Co NP exposure, viability of the cell line MG-63 was reduced in a dose- and time-dependent manner. Also, retraction of cellular pseudopods, pyknosis of the cytoplasm, and cell death was observed. Further, Co NPs inhibited osteoblastic function and differentiation by affecting mRNA and protein expression levels of genes such as ALP, BGLAP, Col I, OGP, and $R A N K L .{ }^{105}$ This suggests that Co NPs do not only suppress the osteoblastic growth and differentiation, but also indirectly upregulate osteoclastic function. Similar results have been observed on Saos-2 cells. ${ }^{106}$ They showed a reduction in viability after Co NP exposure at 24 hours while Ti NPs had no effect. This indicated that Co NPs were more cytotoxic than Ti NPs. ${ }^{66}$ Moreover, decreased mineralization ability, elasticity, spring constant, and increased apoptosis seemed more pronounced by Co NPs than Ti NPs. Similar results have been observed using murine MC3T3-E1 osteoblasts: both Co elemental $(30 \mathrm{~nm})$ and Co (II, III) oxide $(50 \mathrm{~nm})$ NPs caused a decline in metabolic activity and osteoblast mineralization ability after a 21-day challenge. ${ }^{67}$ Same-sized Co NPs had a greater impact than the other NPs. Thus, Co NPs seem to be more detrimental to OB than other NPs.

Preedy et al exposed MSCs to Co NPs and found a lower value of elasticity and spring constant without significant effect on cell metabolic activity and viability. Notably, Co induced greater effects than Ti NPs. ${ }^{38}$ Further, independent of impaired proliferation, osteogenic differentiation was strongly impaired by in vivo exposure to MoM-wear NPs, whereas chondrogenesis, adipogenesis, and migration were unaffected. $^{96}$

Ta implants are receiving increasing interest as loadbearing orthopedic biomaterial because of their excellent biocompatibility, superior strength, as well as corrosion resistance properties. In the orthopedic field, this transition metal was primarily applied as void filling implant material for 
components in revision hip and knee arthroplasty. ${ }^{41,42}$ Porous Ta has been manufactured by coating Ta NPs onto scaffolds. This special component facilitates a high degree of porosity with fully interconnecting pores which results in mechanical properties close to those of human bone and allows for bone ingrowth. $^{107-110}$

During loading wear, nanoscale Ta particles are inevitably released from implant surface. In total hip/knee arthroplasty implant failure cases, analysis revealed the release of Tacontaining particles. ${ }^{111}$ Recently, exposure of Ta-containing NPs (median diameter $=14.2 \mathrm{~nm}$ ) has been identified after implantation failure of $\mathrm{Ta}$ hip components in vivo. ${ }^{112}$ However, the size, morphology, and composition of Ta particles still warrant further studies, so do their systemic effects and long-term consequences.

\section{Effects of Ta NPs on Peri-Implant Cells}

Previous studies focusing on Ta NPs have reported multiple promising functional changes such as enhanced $\mathrm{OB}$ adhesion, proliferation, ${ }^{109,113}$ MSC differentiation ${ }^{114,115}$ as well as inhibited osteoclast differentiation ${ }^{116}$ on tantalum substrates. However, the interaction of nanoscale Ta particles with peri-implant cells was seldom investigated. Thus, more studies are needed to fully elucidate these aspects.

To date, only two papers concerning Ta NPs and osteoblasts were published. Ta NPs induced autophagy in MC3T3E1 cells and promoted cell viability at a low concentration. ${ }^{117,118}$ This was indicated by upregulated LC3II protein expression, autophagic vesicle ultrastructure, and downregulated p62 expression, suggesting an active cytoprotective role through degradation of hazardous substances. The effect was further confirmed using the autophagy inducer rapamycin and the autophagy inhibitor 3-methyladenine (3-MA). However, reduced viability was observed at concentrations $\geq 25 \mu \mathrm{g} / \mathrm{mL}$ as autophagosome degradation was inhibited and autophagic flux was impaired, as the degradation of p62 was not continuously increased. ${ }^{118}$ These results suggest that Ta NPs can promote autophagy activation which could be a potential key factor in osteoblastic reaction to Ta NPs. Such a dose-dependent switch from pro-survival to cytotoxic response has been documented for rare earth oxide NPs. ${ }^{119,120}$ The dual role could be attributed to the fact that autophagy plays protective roles within its threshold range, which may be attributed to their role in anti-oxidative stress, ${ }^{121}$ clearance of material, and damaged cellular organelles. However, when particle concentration continues to increase, the protective effect may reach its limit, and therefore cell death is inevitable. ${ }^{122,123}$

\section{Ceramic Orthopedic Implant NPs}

Ceramic implant materials were firstly introduced in total hip arthroplasty in $1972 .^{124}$ Over the past 10 years, they have drawn increasing attention in both orthopedic and dental fields because of their excellent tribology and biocompatibility when applied as articulating surfaces in hip and teeth. ${ }^{125,126}$ Current ceramics for orthopedic joint replacement are alumina $\left(\mathrm{Al}_{2} \mathrm{O}_{3}\right)$ and zirconia $\left(\mathrm{ZrO}_{2}\right)$. ${ }^{127}$ $\mathrm{Al}_{2} \mathrm{O}_{3}$ is the primary or continuous phase (70-95\%) and $\mathrm{ZrO}_{2}$ (known as ZTA) is the secondary phase (5\% to $30 \%$ ) used to toughen the $\mathrm{Al}_{2} \mathrm{O}_{3}$. ${ }^{127}$

Because of their excellent characteristics of the tribology, ceramic prosthetic implants offer the lowest wear rates among all bearings for THA and are understandably gaining usage in young and active patients. ${ }^{128}$ Recent systematic reviews also confirmed the safety use of ceramic bearings in TKA. ${ }^{129}$ However, though nanoscale ceramic materials had been identified in failed ceramic joint arthroplasty and were reported to be bioactive, their effects on aseptic loosening remain unclear.

\section{$\mathrm{ZrO}_{2} \mathrm{NPs}$}

Zirconium alloy components with thermally oxidized ceramic $\mathrm{ZrO}_{2}$ bearing surface (approximately $5 \mu \mathrm{m}$ in thickness) have been applied as both femoral and knee components. ${ }^{129,130}$ They have been reported to be with comparable clinical outcomes, rare implant fractures, and lower wear compared with conventional Co-Cr TJA components. ${ }^{130,131}$ However, Zirconium alloy could still undergo rapid accelerated wear if suffering from improper acetabular cup and liner seating or dislocation. ${ }^{132}$ Moreover, $\mathrm{ZrO}_{2}$ NPs are used as bone cement additives (radiopacifier), and nanostructured $\mathrm{ZrO}_{2}$ are used as surface coating material of orthopedic implants. ${ }^{133,134}$ Thus, nano-scaled $\mathrm{ZrO}_{2}$ particles could be released during in vivo abrasion.

Until now, there have been just a few retrieval studies identifying the characteristics of released $\mathrm{ZrO}_{2}$ NPs after aseptic loosening of joint arthroplasty implants (plain PMMA cement with $\mathrm{ZrO}_{2}$ radiopacifier). ${ }^{135}$ Also, the foreign body reactions to nanosized $\mathrm{ZrO}_{2}$ particles have not been fully investigated.

\section{Effects of Zirconia NPs on Macrophages and Osteoclasts}

Silge et al reported that $\mathrm{ZrO}_{2}$ NPs could be internalized by RAW 264.7 cells in vitro. ${ }^{136}$ Further, Vennemann et al reported that engulfed $\mathrm{ZrO}_{2}$ NPs $(9-10 \mathrm{~nm}$ ) can elicit inflammatory and toxic effects on mouse alveolar 
macrophages in vitro, but not in vivo. ${ }^{137}$ Moreover, after wear particle phagocytosis, macrophages also release proinflammatory cytokines (eg, TNF $\alpha$, IL-1).

Micrometer-sized $\mathrm{ZrO}_{2}$ particles $(1.75 \pm 4.66 \mu \mathrm{m})$ have been reported to have a direct stimulatory effect on mature human osteoclast function in vitro and thus promote OCmediated bone resorption. ${ }^{138}$ However, little is known about nano-sized wear particles on OCs. Thus, more studies are needed to fully elucidate this aspect.

\section{Effects of Zirconia NPs on Osteoblasts and MSCs}

$\mathrm{ZrO}_{2}$ NPs revealed a significant dose-dependent (from 15 ppm to $150 \mathrm{ppm}$ ) decrease in viability of MG-63 cells and L929 cells at 24 hours, while $\mathrm{Al}_{2} \mathrm{O}_{3}$ NPs had no detectable adverse effect. They also elevated TNF $\alpha$ production of RAW 264.7 cells at 24 hours. $\mathrm{Al}_{2} \mathrm{O}_{3}, \mathrm{ZrO}_{2}$ and silicon nitride $\left(\mathrm{Si}_{3} \mathrm{~N}_{4}\right)$ NPs significantly promoted ALP activity in MG-63 cells. Interestingly, $\mathrm{Al}_{2} \mathrm{O}_{3} \mathrm{NPs}$ promoted ALP activity at low concentrations without irritating macrophages in vitro. ${ }^{139}$

$\mathrm{ZrO}_{2} \mathrm{NPs}(31.9 \pm 1.9 \mathrm{~nm})$ induced MC3T3-E1 cell shrinkage in vitro, with pyknosis-like nuclei, condensed unclear actin filaments as well as more potent cytoskeleton disruption than $\mathrm{TiO}_{2}$ NPs. At concentrations of $100 \mu \mathrm{g} / \mathrm{mL}, \mathrm{ZrO}_{2}$ NPs could induce ROS-dependent cytotoxic effects in time- and concentration-dependent manners and showed inhibitory effects on osteogenic differentiation and mineralization of MC3T3-E1 cells in vitro. Further in this study, $\mathrm{ZrO}_{2} \mathrm{NPs}$ induced more potent toxic and oxidative stress effects than $\mathrm{TiO}_{2}$ NPs $(25.4 \pm 2.8 \mathrm{~nm}) .{ }^{140}$ These results indicated that both $\mathrm{ZrO}_{2}$ and $\mathrm{TiO}_{2}$ NPs are unable to maintain their biocompatibility at higher does. In contrast to this, a different study did not observe reduced viability in osteoblasts and MG-63 after $\mathrm{ZrO}_{2}$ NPs challenge. ${ }^{141}$ This discrepancy may be attributed to the diversity of cell culture protocols, procedures, reagents, and biomaterials used and argues for more standardized studies to compare results on the cell biological effects of NPs.

After exposure to different synthesized yttria-stabilized $\mathrm{ZrO}_{2} \mathrm{NPs}$ (approximately $7 \mathrm{~nm}$ in size), rat BMSCs exhibited normal morphology spreading patterns but lower adhesion density in comparison to the control. ${ }^{142}$ Also, both $\mathrm{ZrO}_{2}$ and pure-Ti NPs dose- and time-dependently compromised human BMSC viability through apoptosis induction. Notably, $\mathrm{ZrO}_{2}$ elicited less cytotoxicity than Ti particles. ${ }^{143}$

\section{$\mathrm{Al}_{2} \mathrm{O}_{3} \mathrm{NPs}$}

$\mathrm{Al}_{2} \mathrm{O}_{3}$ NPs are important ceramic materials that have been used in a variety of commercial and industrial applications. Based on their applications, the most likely scenario for their exposure is inhalation during bulk manufacturing and handling of freely dispersible NPs at the workplace. With the wide application of ceramic orthopedic implants, ceramic prostheses also have been the internal source of $\mathrm{Al}_{2} \mathrm{O}_{3}$ NPs. Due to the limitation of the light microscope, previous histological studies of retrieval tissues from uncemented ceramic-on-ceramic prostheses only alumina particles with micrometer-sized particles were described. ${ }^{144,145}$ In 2002, Hatton et al firstly identified nanometer-sized $\mathrm{Al}_{2} \mathrm{O}_{3}$ wear debris in the size range of 5-90 $\mathrm{nm}(24 \pm 19 \mathrm{~nm})$ by transmission electron microscopy (TEM). ${ }^{146}$ Yet, very few studies have evaluated the risk associated with these nanomaterials.

\section{Effects of $\mathrm{Al}_{2} \mathrm{O}_{3} \mathrm{NPs}$ on Macrophages}

Kim studied the inhalation toxicity of $\mathrm{Al}_{2} \mathrm{O}_{3} \mathrm{NPs}$ in rats with a nose-only inhalation system. Histopathology showed marked alveolar macrophage accumulation in the lungs and revealed that the lung was the primary target organ. Also, significantly increased inflammation was evidenced by elevated TNF $\alpha$ and IL-6 level in bronchoalveolar lavage fluid. ${ }^{147}$ In accordance with this in vivo study, $\mathrm{Al}_{2} \mathrm{O}_{3}$ NPs have been shown to induce acute inflammation in macrophages in vitro. Hashimoto et al exposed RAW 264 macrophages and $\mathrm{L} 929$ fibroblasts to $\mathrm{Al}_{2} \mathrm{O}_{3}$ NPs (13 $\mathrm{nm}$ diameter) as well as $\mathrm{Al}_{2} \mathrm{O}_{3}$ nanowires $(2-6 \times 200-400$ $\mathrm{nm})$. The $\mathrm{Al}_{2} \mathrm{O}_{3} \mathrm{NPs}$ showed more significant cytotoxicity as well as cell structural and nuclear damage compared to nanowires. ${ }^{148}$ Compared to other conditions, only $\mathrm{Al}_{2} \mathrm{O}_{3}$ $(20 \mathrm{~nm}) \mathrm{NPs}$ at high concentration $(1000 \mu \mathrm{g} / \mathrm{mL})$ could induce a prominent acute ROS release in RAW 264.7 macrophages, ${ }^{149}$ suggesting that $\mathrm{Al}_{2} \mathrm{O}_{3}$ NPs are relatively biocompatible. These results support the inert biological behavior of ceramic biomaterials.

Being used along with vaccines as immune system adjuvants and are known to activate the NLRP3 inflammasome, $\mathrm{Al}_{2} \mathrm{O}_{3}$ NPs and aluminum-coated nanomaterial treatment upregulated the pro-inflammatory cytokine expression in macrophages. ${ }^{150,151}$ In contrast, there were also other studies reporting $\mathrm{Al}_{2} \mathrm{O}_{3}$ NPs impairing macrophages' natural ability to respond to bacteria and antigen-mediated inflammation. More specifically, even at non-toxic concentrations, both $\mathrm{Al}_{2} \mathrm{O}_{3}$ NPs and $\mathrm{Al}$ NPs could impair the phagocytosis of community-associated methicillin-resistant Staphylococcus aureus (ca-MRSA). They also repressed the secretion of cytokines such as IL-1, IL-6, and TNF $\alpha$ under ca-MRSA stimulation via suppressing the NF- $\kappa \mathrm{B}$ pathway. ${ }^{152}$ These results suggest that $\mathrm{Al}_{2} \mathrm{O}_{3}$ NPs change macrophages' natural ability to respond to pathogens. 


\section{Effects of $\mathrm{Al}_{2} \mathrm{O}_{3} \mathrm{NPs}$ on Osteoblasts and MSCs}

Recent studies showed that $\mathrm{Al}_{2} \mathrm{O}_{3}(50 \mathrm{~nm})$ and $\mathrm{TiO}_{2}$ (anatase, $15 \mathrm{~nm}$ ) can be internalized and cause cytotoxicity in rat osteoblast-like UMR 106 cells. ${ }^{153}$ In another study conducted by Zhang et al, $\mathrm{Al}_{2} \mathrm{O}_{3}$ NPs $(40-50 \mathrm{~nm})$ induced no detectable adverse effect on MG-63 cells in MTT and total intracellular protein (TCP) assays. Interestingly, $\mathrm{Al}_{2} \mathrm{O}_{3}$ NPs increased ALP activity at low doses (15 ppm) and decreased it at high doses (500 ppm). This is different from $\mathrm{ZrO}_{2} \mathrm{NPs}$, which decreased ALP activity at $15 \mathrm{ppm}$ while dramatically increasing it at $500 \mathrm{ppm} .{ }^{139}$ Further, $\mathrm{Al}_{2} \mathrm{O}_{3}$ NPs $(<1 \mu \mathrm{m})$ dose-dependently increased ALP activity while $1-10 \mu \mathrm{m}$ particles did not such property. This suggests that both the sizes and composition of the $\mathrm{Al}_{2} \mathrm{O}_{3}$ NPs might influence their effect on osteoblast function, which is similar to the results in osteoblasts.

MSCs can also take up $\mathrm{Al}_{2} \mathrm{O}_{3}$ NPs and demonstrated intracellular morphological changes such as cytoplasmic vacuolization, nuclear and DNA fragmentation. ${ }^{154}$ In addition, $\mathrm{Al}_{2} \mathrm{O}_{3}$ NPs could reduce the viability of human MSCs in a dose- and time-dependent manner by arresting cell cycle progression. More specifically, the cell cycle was arrested in the sub-G0/G1 phase, accompanied by a reduced percentage of cells in the G0/G1 phase and $\mathrm{G} 2 / \mathrm{M}$ phase.

Interestingly, nanosized $\mathrm{Al}_{2} \mathrm{O}_{3}$ particles $(<50 \mathrm{~nm})$ have been reported to promote fibroblastic autophagy, which negatively regulated RANKL expression and osteolysis, both in vitro and in vivo. ${ }^{155}$ Further, $\mathrm{Al}_{2} \mathrm{O}_{3}$ NPs $(<50$ $\mathrm{nm}$ ) could evoke autophagy and even counter Ti particleinduced apoptosis, NF- $\mathrm{kB}$ activation, and inflammatory reactions both in MG-63 cells and a mouse calvarial osteolysis model. ${ }^{156}$ This suggests that $\mathrm{Al}_{2} \mathrm{O}_{3}$ NPs play a protective role in Ti particle-induced osteolysis through preventing autophagy, reducing apoptosis, and inflammation. Thus, though ceramic material seems to be biocompatible and has advantageous properties, ceramic NPs' adverse biological effects should not be neglected. Future studies should focus on elucidating the underlying molecular pathogenesis of ceramic NPs on peri-implant cells.

\section{Limitations and Future Perspective}

This review updates the characteristics of metallic and ceramic NPs generated after prosthesis implantation and summarizes their biological impact on peri-prosthetic cell lineages. Future studies analyzing other types of nano-scale wear debris, such as polyethylene, PMMA, are necessary, in order to understand the problem of implant loosening as a whole. Also, different implant biomaterials generate wear particles of different types, sizes, shapes, and their impact on peri-implant cells is dependent on the material type. Thus, elucidation of the reasons for these differences would be a starting point for planning material-specific targeting of peri-prosthetic osteolysis.

Second, retrieved particles from loosened implants and primary cells or animal models should be advocated in future studies as they are more relevant to the in vivo conditions found in patients. Nevertheless, because of technical reasons, there are still difficulties associated with the precise and truly qualitative analysis of nanosized particles from clinical samples. ${ }^{157}$ Scanning electron microscopy has revealed that particulate materials generated from implant wear vary more greatly in shape than commercially produced particles and are more detrimental or inflammatory to peri-implant tissues. This suggests that the number and biological severity of actually produced NPs may have been underestimated. Thus, current protocols and instruments for effectively isolating and characterizing NPs from clinical samples should be updated in order to accurately define its clinical pathological effects in the future.

Third, with prosthetic biomaterial manufacturing techniques developing, coating novel orthopedic implants with wear-resistant material (such as $\mathrm{TiN}_{3}$ ) or including slowreleasing drugs within the prostheses may offer a promising option to mitigate peri-prosthetic osteolysis and extend implant's life span. Moreover, as several pathways or molecular mechanisms (eg, ROS-dependent pathway, SIRT1-NF $-\kappa \mathrm{B}$, autophagy) have been identified during the pathology of wear debris-associated osteolysis (Table 1), further studies are required for developing drugs targeting these pathways and mechanisms to curtail aseptic loosening. However, although some drugs targeting specific cells have demonstrated efficacy in vitro and even in animal models, their translational potential remains to be established. More specifically, many of them are not specific to one cell lineage and may thus cause diverse and systematic adverse effects. Given the fact that multiple peri-implant cells contribute to the development of aseptic loosening, pharmacological blockade of one signaling pathway in one cell type alone is unlikely to successfully alleviate the overall effects of wear particles. Thus, a combination of pharmacologically targeting multiple peri-implant cells as well as their related pathological pathways may be a feasible strategy to curtail wear particleinduced peri-prosthetic osteolysis in the future. However, improvements in the specificity, safety, and manipulability 
Table I Summary of Pathways of Wear Particle-Associated Osteolysis

\begin{tabular}{|c|c|c|c|c|c|c|}
\hline NP type & Particle size & Cells/Models & Pathways & Action & Effect & References \\
\hline Ti alloy & $<100 \mathrm{~nm}$ & $\begin{array}{l}\text { Primary rabbit } \\
\text { BMSCs }\end{array}$ & Bax/Caspase-3 & Activator & MSC apoptosis $\uparrow$ & 37 \\
\hline $\mathrm{Ti}$ & $52.59 \pm 20.48 \mathrm{~nm}$ & $\begin{array}{l}\text { RAW264.7 and } \\
\text { mouse air pouch } \\
\text { model }\end{array}$ & $\begin{array}{l}\text { MAPK (ERK/ } \\
\text { P38) }\end{array}$ & Activator & $\begin{array}{l}\text { MI polarization } \uparrow \text {, inflammation } \uparrow \text {, } \\
\text { indirectly inhibit osteogenic } \\
\text { differentiation of rat BMSCs }\end{array}$ & 58 \\
\hline $\begin{array}{l}\text { TiAl6V4, } \\
\text { CoCrMo }\end{array}$ & $<180 \mathrm{~nm}$ & $\begin{array}{l}\text { RAW264.7 and } \\
\text { mouse PIO model }\end{array}$ & SIRTI-NF-KB & Activator & $\begin{array}{l}\text { Macrophage inflammatory reaction in } \\
\text { vitro } \uparrow \text { Inflammatory reaction and } \\
\text { osteolysis in PIO animal models } \uparrow\end{array}$ & 59 \\
\hline $\mathrm{TiO}_{2}$ & $5 \mathrm{~nm}$ and $40 \mathrm{~nm}$ & $\mathrm{SaOS}-2$ & FAK signaling & Activator & Adhesion $\downarrow$ & 84 \\
\hline $\mathrm{TiO}_{2}$ & $10 \mathrm{~nm}$ & $\begin{array}{l}\text { RAW264.7, mouse } \\
\text { BMDM }\end{array}$ & Cox-2 & Activator & Inflammatory response $\uparrow$ & 75 \\
\hline $\mathrm{TiO}_{2}$ & $20 \mathrm{~nm}$ & RAW264.7 & $\begin{array}{l}\text { TLRs- } \\
\text { P38MAPK and } \\
\text { SAPK/JNK }\end{array}$ & Activator & Apoptosis $\uparrow$, inflammatory response $\uparrow$ & 78 \\
\hline $\mathrm{TiO}_{2}$ & NA & $\begin{array}{l}\text { THP-I-derived } \\
\text { macrophages and } \\
\text { BMDMs }\end{array}$ & $\begin{array}{l}\text { PLC- } \beta / \text { InsP3- } \\
\text { NLRP3 } \\
\text { inflammasome }\end{array}$ & Activator & Inflammatory response $\uparrow$ & 79 \\
\hline $\mathrm{TiO}_{2}$ & NA & $\begin{array}{l}\text { THP-I-derived } \\
\text { macrophages and } \\
\text { BMDMs }\end{array}$ & $\begin{array}{l}\text { ADCY-cAMP- } \\
\text { NLRP3 } \\
\text { inflammasome }\end{array}$ & Inhibitor & Inflammatory response $\uparrow$ & 79 \\
\hline $\mathrm{TiO}_{2}$ & $10 \mathrm{~nm}, 30-40 \mathrm{~nm}$ & $\begin{array}{l}\text { THP-I-derived } \\
\text { macrophages }\end{array}$ & $\begin{array}{l}\text { ROS/ } \\
\text { Cathepsin B- } \\
\text { NLRP3 } \\
\text { inflammasome }\end{array}$ & Activator & Inflammatory response $\uparrow$ & 80 \\
\hline Co & $28 \mathrm{~nm}$ & $\begin{array}{l}\text { U937, human } \\
\text { macrophages }\end{array}$ & HIF pathway & Activator & Cytotoxicity $\uparrow$ & 103 \\
\hline Co & $2-60 \mathrm{~nm}$ & $\begin{array}{l}\text { Human macrophages } \\
\text { and mouse } \\
\text { intraperitoneal } \\
\text { model }\end{array}$ & ROS-RhoA & Inhibitor & Macrophage motility $\downarrow$ & 104 \\
\hline $\mathrm{Ta}$ & $41.89 \pm 19.58 \mathrm{~nm}$ & МСЗТ3-EI & Autophagy & $\begin{array}{l}\text { Activator/ } \\
\text { Inhibitor }\end{array}$ & $\begin{array}{l}\text { Increase osteoblastic viability during } \\
\text { proliferation at low concentration, while } \\
\text { inhibit at high concentration }\end{array}$ & 117,118 \\
\hline $\mathrm{ZrO}_{2}$ & $31.9 \pm 1.9 \mathrm{~nm}$ & МСЗТЗ-EI & ROS & Activator & Cytotoxicity $\uparrow$ & 140 \\
\hline $\mathrm{TiO}_{2}$ & $25.4 \pm 2.8 \mathrm{~nm}$ & МС3ТЗ-EI & ROS & Activator & Cytotoxicity $\uparrow$ & 140 \\
\hline $\mathrm{Al}_{2} \mathrm{O}_{3}$ & $<50 \mathrm{~nm}$ & $\begin{array}{l}\text { MG63 and mouse } \\
\text { PIO model }\end{array}$ & $\begin{array}{l}\text { Autophagy, } \\
\text { NF-kB, } \\
\text { Caspase-3 }\end{array}$ & Inhibitor & $\begin{array}{l}\text { Apoptosis } \downarrow \text {, inflammation } \downarrow \text {, osteogenic } \\
\text { activity } \uparrow \text {, OPG } \uparrow \text {, osteolysis in PIO } \\
\text { model } \downarrow\end{array}$ & 156 \\
\hline
\end{tabular}

Abbreviations: $\mathrm{ADCY}$, adenylate cyclase; $\mathrm{Al}_{2} \mathrm{O}_{3}$, aluminum oxide; $\mathrm{BMDM}$, bone marrow-derived macrophages; $\mathrm{BMSCs}$, bone marrow mesenchymal stem cells; Co, cobalt; FAK, focal adhesion kinase; HIF, hypoxia-inducible factor; MAPK, mitogen-activated protein kinase; NF- $\mathrm{kB}$, nuclear factor- $\kappa$; NLRP3, NOD-like receptor pyrin domaincontaining-3; OPG, osteoprotegerin; PIO, particle-induced osteolysis; RhoA, ras homolog gene family, member A; ROS, reactive oxygen species; SIRT, sirtuin; Ta, tantalum; $\mathrm{Ti}$, titanium; TLRs, toll-like receptors; $\mathrm{TiO}_{2}$, titanium dioxide; $\mathrm{ZrO}_{2}$, zirconium oxide; $\uparrow$, upregulated; $\downarrow$, downregulated. 


\section{Macrophages MSCs}

\begin{tabular}{|l|}
\hline 1. Cytotoxicity $\uparrow$ \\
2. M1 Polarization $\uparrow$ \\
3. Motility et al $\downarrow$ \\
4. Inflammasome activation $\uparrow$ \\
5. Inflammatory reaction $\uparrow$ \\
6. Phagocytic capability $\downarrow$
\end{tabular}
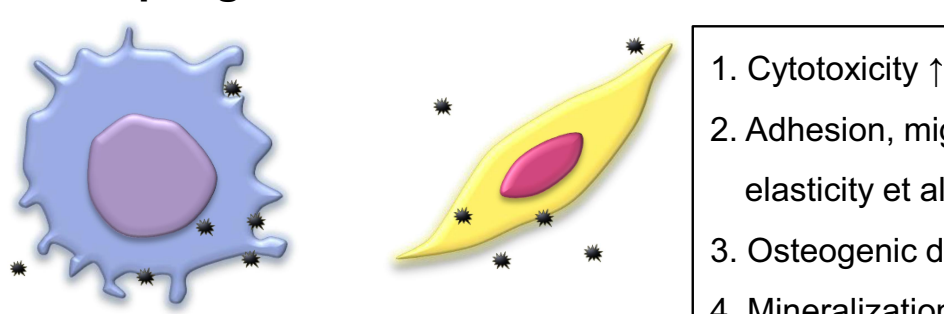

2. Adhesion, migration, elasticity et al $\downarrow$

3. Osteogenic differentiation $\downarrow$

4. Mineralization $\downarrow$

\section{Cytotoxicity $\uparrow$ \\ 2. Migration, adhesion et al $\downarrow$ \\ 3. Autophagy $\uparrow$ \\ 4. Osteogenic differentiation $\downarrow$ \\ 5. Mineralization $\downarrow$ \\ 6. Inflammatory reaction \\ 7. OPG $\downarrow$, RANKL $\uparrow$}

Figure I Wear particles pose adverse effects on general cellular functions of peri-implant cells such as viability, adhesion and migration. They also upregulate proinflammatory mediators in macrophages and osteoblasts, which contribute to a chronic inflammatory peri-implant environment and osteoclastogenesis. Moreover, they impair osteogenic differentiation and matrix mineralization of osteoblasts and mesenchymal stem cells. These effects not only impede new bone formation but also favor osteoclastic bone resorption. $\uparrow$ indicates upregulation, $\downarrow$ indicates downregulation.

Abbreviations: MSCs, mesenchymal stem cells; NPs, nanoparticles; OPG, osteoprotegerin; RANKL, receptor activator of nuclear factor (NF)-kB ligand.

of these drugs are needed before they can be considered for clinical application.

\section{Conclusion}

Wear particles can target peri-prosthetic cells by disrupting multiple cellular functions (eg, cell survival, osteogenic differentiation, mineralization), inducing an inflammatory environment, and activating/inhibiting different pathways. These reactions alter the balance between osteoblastic bone formation and osteoclastic bone resorption, thereby promoting periprosthetic osteolysis and ultimately leading to implant loosening (Figure 1). Future studies are needed to further explore the effect of different nano-sized wear particles on peri-implant cells and their underlying molecular pathogenesis for the development of effective pharmacological interventions.

\section{Abbreviations}

$\mathrm{Al}_{2} \mathrm{O}_{3}$, alumina; ALP, alkaline phosphatase; BMDMs, bone marrow-derived macrophages; BMP-2, bone morphogenetic protein 2; ca-MRSA, communityassociated methicillin-resistant Staphylococcus aureus; Co, cobalt; $\mathrm{Cr}$, chromium; HIF, hypoxia-inducible factor; LMP, lysosomal membrane permeabilization; M-CSF, macrophage-colony stimulating factor; $\mathrm{MOM}$, metal-onmetal; MOP, metal-on-polyethylene; MSCs, mesenchymal stem cells; NFATc1, nuclear factor of activated T-cells cytoplasmic 1; NPs, nanoparticles; OCN, osteocalcin; OPG, osteoprotegerin; OPN, osteopontin; OsteoMacs, osteal tissue macrophage; PIO, particle-induced osteolysis; RANKL, receptor activator of nuclear factor (NF)- $\mathrm{kB}$ ligand; $\mathrm{Si}_{3} \mathrm{~N}_{4}$ : silicon nitride; THA, total hip arthroplasty; TJA, total joint arthroplasty; Ta, tantalum; TEM, transmission electron microscopy; $\mathrm{Ti}$, titanium; $\mathrm{TiO}_{2}$, titanium dioxide; VEGF, vascular endothelial growth factor; $\mathrm{ZrO}_{2}$, zirconia; 3-MA, 3-methyladenine.

\section{Acknowledgment}

Li Zhang wants to thank Dr. Shu Chen for all her help and support. 


\section{Author Contributions}

All authors made substantial contributions to conception and design, acquisition of data, or analysis and interpretation of data; took part in drafting the article or revising it critically for important intellectual content; gave final approval of the version to be published; and agree to be accountable for all aspects of the work.

\section{Disclosure}

The authors report no conflicts of interest in this work.

\section{References}

1. Saleh KJ, Schwarz EM. Osteolysis: medical and surgical approaches. Clin Orthopaed Related Res. 2004;427:138-147. doi:10.1097/01.blo.0000142288.66246.4d

2. Kenney C, Dick S, Lea J, Liu J, Ebraheim NA. A systematic review of the causes of failure of revision total hip arthroplasty. J Orthop. 2019;16(5):393-395. doi:10.1016/j.jor.2019.04.011

3. Khan M, Osman K, Green G, Haddad FS. The epidemiology of failure in total knee arthroplasty: avoiding your next revision. Bone Joint J. 2016;98-B(1 Suppl A):105-112. doi:10.1302/ 0301-620X.98B1.36293

4. Espinosa N, Klammer G, Wirth SH. Osteolysis in total ankle replacement: how does it work? Foot Ankle Clin. 2017;22 (2):267-275. doi:10.1016/j.fcl.2017.01.001

5. Sadoghi P, Liebensteiner M, Agreiter M, Leithner A, Böhler N, Labek G. Revision surgery after total joint arthroplasty: a complication-based analysis using worldwide arthroplasty registers. J Arthroplasty. 2013;28(8):1329-1332. doi:10.1016/j.arth.2013.01.012

6. Prkic A, Welsink C, van den Bekerom MP, Eygendaal D, Eygendaal D. Why does total elbow arthroplasty fail today? A systematic review of recent literature. Arch Orthop Trauma Surg. 2017;137(6):761-769. doi:10.1007/s00402-017-2687-x

7. Bozic KJ, Kamath AF, Ong K, et al. Comparative epidemiology of revision arthroplasty: failed THA poses greater clinical and economic burdens than failed TKA. Clin Orthopaed Related Res. 2015;473(6):2131-2138. doi:10.1007/s11999-014-4078-8

8. Schipper ON, Haddad SL, Pytel P, Zhou Y. Histological analysis of early osteolysis in total ankle arthroplasty. Foot Ankle Int. 2017;38(4):351-359. doi:10.1177/1071100716682333

9. Schmalzried T, Jasty M, Harris WH. Periprosthetic bone loss in total hip arthroplasty. Polyethylene wear debris and the concept of the effective joint space. J Bone Joint Surg Am. 1992;74 (6):849-863. doi:10.2106/00004623-199274060-00006

10. Hirakawa K, Bauer TW, Stulberg BN, Wilde AH. Comparison and quantitation of wear debris of failed total hip and total knee arthroplasty. J Biomed Mater Res. 1996;31(2):257-263. doi:10.1002/(SICI)10974636(199606)31:2<257::AID-JBM13>3.0.CO;2-I

11. Margevicius KJ, Bauer TW, McMahon JT, Brown SA, Merritt K. Isolation and characterization of debris in membranes around total joint prostheses. JBJS. 1994;76(11):1664-1675. doi:10.2106/ 00004623-199411000-00010

12. Hall DJ, Pourzal R, Jacobs JJ, Urban RM. Metal wear particles in hematopoietic marrow of the axial skeleton in patients with prior revision for mechanical failure of a hip or knee arthroplasty. J Biomed Mater Res B Appl Biomater. 2019;107(6):1930-1936. doi:10.1002/jbm.b.34285

13. Urban RM, Tomlinson MJ, Hall DJ, Jacobs JJ. Accumulation in liver and spleen of metal particles generated at nonbearing surfaces in hip arthroplasty. J Arthroplasty. 2004;19(8):94-101. doi:10.1016/j.arth.2004.09.013
14. Keegan GM, Learmonth ID, Case C. A systematic comparison of the actual, potential, and theoretical health effects of cobalt and chromium exposures from industry and surgical implants. Crit Rev Toxicol. 2008;38(8):645-674. doi:10.1080/10408440701845534

15. Engh Jr CA E, Moore KD, Vinh TN, Engh GA. Titanium prosthetic wear debris in remote bone marrow. A report of two cases. JBJS. 1997;79(11):1721-1725. doi:10.2106/00004623-199711000-00014

16. Papageorgiou I, Brown C, Schins R, et al. The effect of nano-and micron-sized particles of cobalt-chromium alloy on human fibroblasts in vitro. Biomaterials. 2007;28(19):2946-2958. doi:10.10 16/j.biomaterials.2007.02.034

17. Billi F, Campbell P. Nanotoxicology of metal wear particles in total joint arthroplasty: a review of current concepts. $J$ Applied Biomater Biomech. 2010;8(1):1-6.

18. Ingham $E$, Fisher $J$. The role of macrophages in osteolysis of total joint replacement. Biomaterials. 2005;26(11):1271-1286. doi:10. 1016/j.biomaterials.2004.04.035

19. Nich C, Takakubo Y, Pajarinen J, et al. Macrophages - key cells in the response to wear debris from joint replacements. $J$ Biomed Mater Res A. 2013;101(10):3033-3045. doi:10.1002/jbm.a.34599

20. Cho SW. Role of osteal macrophages in bone metabolism. J Pathol Translat Med. 2015;49(2):102. doi:10.4132/jptm.2015. 02.02

21. Rao AJ, Gibon E, Ma T, Yao Z, Smith RL, Goodman SB. Revision joint replacement, wear particles, and macrophage polarization. Acta Biomater. 2012;8(7):2815-2823. doi:10.1016/ j.actbio.2012.03.042

22. Tee S-Y, Fu J, Chen CS, Janmey PA. Cell shape and substrate rigidity both regulate cell stiffness. Biophys J. 2011;100(5):L25L27. doi:10.1016/j.bpj.2010.12.3744

23. Moutzouri AG, Athanassiou GM. Insights into the alteration of osteoblast mechanical properties upon adhesion on chitosan. Biomed Res Int. 2014;2014:1-8. doi:10.1155/2014/ 740726

24. Vallés G, Pérez C, Boré A, Martín-Saavedra F, Saldaña L, Vilaboa N. Simvastatin prevents the induction of interleukin-6 gene expression by titanium particles in human osteoblastic cells. Acta Biomater. 2013;9(1):4916-4925. doi:10.1016/j.actbio.2012. 08.027

25. Lochner K, Fritsche A, Jonitz A, et al. The potential role of human osteoblasts for periprosthetic osteolysis following exposure to wear particles. Int J Mol Med. 2011;28(6):1055-1063. doi:10.3892/ijmm.2011.778

26. Park JH, Lee NK, Lee SY. Current understanding of RANK signaling in osteoclast differentiation and maturation. Mol Cells. 2017;40(10):706.

27. Meng B, Yang X, Chen Y, Zhai J, Liang X. Effect of titanium particles on osteoclast activity in vitro. Mol Med Rep. 2010;3 (6):1065-1069. doi:10.3892/mmr.2010.368

28. Hallab NJ, Jacobs JJ. Chemokines associated with pathologic responses to orthopedic implant debris. Front Endocrinol (Lausanne). 2017;8:5. doi:10.3389/fendo.2017.00005

29. Yadav J, Samelko L, Gilvar P, McAllister K, Hallab NJ. Osteoclasts lose innate inflammatory reactivity to metal and polymer implant debris compared to monocytes/macrophages. Open Orthop J. 2013;7(1):605. doi:10.2174/1874325001307010605

30. Pajarinen J, Lin T, Nabeshima A, et al. Mesenchymal stem cells in the aseptic loosening of total joint replacements. J Biomed Mater Res A. 2017;105(4):1195-1207. doi:10.1002/jbm.a.35978

31. Greulich C, Diendorf J, Simon T, Eggeler G, Epple M, Köller M. Uptake and intracellular distribution of silver nanoparticles in human mesenchymal stem cells. Acta Biomater. 2011;7 (1):347-354. doi:10.1016/j.actbio.2010.08.003

32. Wu M, Gu L, Gong Q, et al. Strategies to reduce the intracellular effects of iron oxide nanoparticle degradation. Nanomedicine. 2017;12(5):555-570. doi:10.2217/nnm-2016-0328 
33. Wu J, Yin GF, Chen HQ, Sung KLP. The influence of titanium particles size on bone marrow mensenchymal stem cells viability. Key Eng Mater. 2014. 1063-1066.

34. Hackenberg S, Scherzed A, Technau A, Froelich K, Hagen R, Kleinsasser N. Functional responses of human adipose tissue-derived mesenchymal stem cells to metal oxide nanoparticles in vitro. J Biomed Nanotechnol. 2013;9(1):86-95. doi:10.1166/jbn.2013.1473

35. Jiang Y, Jia T, Gong W, Wooley PH, Yang SY. Effects of Ti, PMMA, UHMWPE, and Co-Cr wear particles on differentiation and functions of bone marrow stromal cells. J Biomed Mater Res A. 2013;101(10):2817-2825. doi:10.1002/jbm.a.34595

36. Bressan E, Ferroni L, Gardin C, et al. Metal nanoparticles released from dental implant surfaces: potential contribution to chronic inflammation and peri-implant bone loss. Materials. 2019;12(12):2036. doi:10.3390/ma12122036

37. He XB, Ma T, Zheng W, Geng QH, Guo KJ. Nano-sized titanium alloy particles inhibit the proliferation and promote the apoptosis of bone marrow mesenchymal stem cells in vitro. Mol Med Rep. 2018;17(2):2271-2276. doi:10.3892/mmr.2017.8105

38. Preedy EC, Perni S, Prokopovich P. Cobalt and titanium nanoparticles influence on mesenchymal stem cell elasticity and turgidity. Colloids Surf B Biointerfaces. 2017;157:146-156. doi:10.1016/j.colsurfb.2017.05.019

39. Gibon E, Amanatullah DF, Loi F, et al. The biological response to orthopaedic implants for joint replacement: part I: metals. $J$ Biomed Mater Res B Appl Biomater. 2017;105(7):2162-2173. doi:10.1002/jbm.b.33734

40. Gibon E, Córdova LA, Lu L, et al. The biological response to orthopedic implants for joint replacement. II: polyethylene, ceramics, PMMA, and the foreign body reaction. J Biomed Mater Res B Appl Biomater. 2017;105(6):1685-1691. doi:10.1002/jbm.b.33676

41. Abdelaziz H, Jaramillo R, Gehrke T, Ohlmeier M, Citak M. Clinical survivorship of aseptic revision total knee arthroplasty using hinged knees and tantalum cones at minimum 10-year follow-up. J Arthroplasty. 2019;34(12):3018-3022. doi:10.1016/ j.arth.2019.06.057

42. Jenkins DR, Odland AN, Sierra RJ, Hanssen AD, Lewallen DG. Minimum five-year outcomes with porous tantalum acetabular cup and augment construct in complex revision total hip arthroplasty. JBJS. 2017;99(10):e49. doi:10.2106/JBJS.16.00125

43. Lugowski SJ, Smith DC, McHugh AD, Van Loon JC. Release of metal ions from dental implant materials in vivo: determination of $\mathrm{Al}, \mathrm{Co}, \mathrm{Cr}, \mathrm{Mo}, \mathrm{Ni}, \mathrm{V}$, and $\mathrm{Ti}$ in organ tissue. J Biomed Mater Res. 1991;25(12):1443-1458. doi:10.1002/jbm.820251204

44. Feng X, Chen A, Zhang Y, Wang J, Shao L, Wei L. Application of dental nanomaterials: potential toxicity to the central nervous system. Int J Nanomedicine. 2015;10:3547.

45. Goodman SB. Wear particles, periprosthetic osteolysis and the immune system. Biomaterials. 2007;28(34):5044-5048. doi:10.10 16/j.biomaterials.2007.06.035

46. Urban RM, Jacobs JJ, Tomlinson MJ, Gavrilovic J, Black J, Peoc'h M. Dissemination of wear particles to the liver, spleen, and abdominal lymph nodes of patients with hip or knee replacement. JBJS. 2000;82 (4):457. doi:10.2106/00004623-200004000-00002

47. Kaur M, Singh K. Review on titanium and titanium based alloys as biomaterials for orthopaedic applications. Mat Sci Eng C-Mater. 2019;102:844-862. doi:10.1016/j.msec.2019.04.064

48. de Viteri VS, Fuentes E. Titanium and titanium alloys as biomaterials. Tribology. 2013;1:155-181.

49. Shi H, Magaye R, Castranova V, Zhao J. Titanium dioxide nanoparticles: a review of current toxicological data. Part Fibre Toxicol. 2013;10(1):15. doi:10.1186/1743-8977-10-15

50. Yao JJ, Lewallen EA, Trousdale WH, et al. Local cellular responses to titanium dioxide from orthopedic implants. Biores Open Access. 2017;6(1):94-103. doi:10.1089/biores.2017.0017
51. Winkler HC, Notter T, Meyer U, Naegeli H. Critical review of the safety assessment of titanium dioxide additives in food. $J$ Nanobiotechnology. 2018;16(1):51. doi:10.1186/s12951-0180376-8

52. Ruiz PA, Morón B, Becker HM, et al. Titanium dioxide nanoparticles exacerbate DSS-induced colitis: role of the NLRP3 inflammasome. Gut. 2017;66(7):1216-1224. doi:10.1136/gutjnl2015-310297

53. Bouwmeester H, van der Zande M, Jepson MA. Effects of foodborne nanomaterials on gastrointestinal tissues and microbiota. Wiley Interdiscip Rev Nanomed Nanobiotechnol. 2018;10(1): e1481.

54. Abbasi-Oshaghi E, Mirzaei F, Pourjafar M. NLRP3 inflammasome, oxidative stress, and apoptosis induced in the intestine and liver of rats treated with titanium dioxide nanoparticles: in vivo and in vitro study. Int $J$ Nanomedicine. 2019;14:1919. doi:10.2147/IJN.S192382

55. Wang J, Fan Y. Lung injury induced by $\mathrm{TiO} 2$ nanoparticles depends on their structural features: size, shape, crystal phases, and surface coating. Int J Mol Sci. 2014;15(12):22258-22278. doi:10.3390/ijms151222258

56. Prasad RY, Wallace K, Daniel KM, et al. Effect of treatment media on the agglomeration of titanium dioxide nanoparticles: impact on genotoxicity, cellular interaction, and cell cycle. ACS Nano. 2013;7(3):1929-1942. doi:10.1021/nn302280n

57. Yazdi AS, Guarda G, Riteau N, et al. Nanoparticles activate the NLR pyrin domain containing 3 (Nlrp3) inflammasome and cause pulmonary inflammation through release of IL- $1 \alpha$ and IL-1 $\beta$. Procee National Acad Sci. 2010;107(45):19449-19454. doi:10.10 73/pnas. 1008155107

58. Yang C, Wang W, Zhu K, et al. Lithium chloride with immunomodulatory function for regulating titanium nanoparticle-stimulated inflammatory response and accelerating osteogenesis through suppression of MAPK signaling pathway. Int $J$ Nanomedicine. 2019;14:7475. doi:10.2147/IJN.S210834

59. Deng Z, Jin J, Wang Z, Wang Y, Gao Q, Zhao J. The metal nanoparticle-induced inflammatory response is regulated by SIRT1 through NF- $\mathrm{BB}$ deacetylation in aseptic loosening. Int J Nanomedicine. 2017;12:3617. doi:10.2147/IJN.S124661

60. Choi MG, Koh HS, Kluess D, et al. Effects of titanium particle size on osteoblast functions in vitro and in vivo. Proc Natl Acad Sci US A. 2005;102(12):4578-4583. doi:10.1073/pnas.0500693102

61. Gu Y, Wang Z, Shi J, et al. Titanium particle-induced osteogenic inhibition and bone destruction are mediated by the GSK-3beta/ beta-catenin signal pathway. Cell Death Dis. 2017;8(6):e2878.

62. Lee SS, Sharma AR, Choi BS, et al. The effect of TNFalpha secreted from macrophages activated by titanium particles on osteogenic activity regulated by WNT/BMP signaling in osteoprogenitor cells. Biomaterials. 2012;33(17):4251-4263. doi:10.10 16/j.biomaterials.2012.03.005

63. Jiang Y, Jia T, Gong W, Wooley PH, Yang SY. Titanium particle-challenged osteoblasts promote osteoclastogenesis and osteolysis in a murine model of periprosthestic osteolysis. Acta Biomater. 2013;9(7):7564-7572. doi:10.1016/j.actbio.2013.03.010

64. Pioletti DP, Leoni L, Genini D, Takei H, Du P, Corbeil J. Gene expression analysis of osteoblastic cells contacted by orthopedic implant particles. J Biomed Mater Res. 2002;61(3):408-420. doi: $10.1002 /$ jbm. 10218

65. Pioletti DP, Takei H, Kwon SY, Wood D, Sung KL. The cytotoxic effect of titanium particles phagocytosed by osteoblasts. J Biomed Mater Res. 1999;46(3):399-407. doi:10.1002/(SICI)1097-4636(19990905)46:3<399::AID-JBM13>3.0.CO;2-B

66. Perni S, Yang L, Preedy EC, Prokopovich P. Cobalt and Titanium nanoparticles influence on human osteoblast mitochondrial activity and biophysical properties of their cytoskeleton. $J$ Colloid Interface Sci. 2018;531:410-420. doi:10.1016/j.jcis.2018.07.028 
67. Preedy EC, Perni S, Prokopovich P. Cobalt, titanium and PMMA bone cement debris influence on mouse osteoblast cell elasticity, spring constant and calcium production activity. RSC Adv. 2015;5 (102):83885-83898. doi:10.1039/C5RA15390E

68. Gu Y, Wang Z, Shi J, et al. Titanium particle-induced osteogenic inhibition and bone destruction are mediated by the GSK-3 $\beta / \beta$ catenin signal pathway. Cell Death Dis. 2017;8(6):e2878. doi: 10.1038/cddis. 2017.275

69. Geng D, Wu J, Shao H, et al. Pharmaceutical inhibition of glycogen synthetase kinase 3 beta suppresses wear debris-induced osteolysis. Biomaterials. 2015;69:12-21. doi:10. 1016/j.biomaterials.2015.07.061

70. Ping $\mathrm{Z}, \mathrm{Hu} \mathrm{X}$, Wang $\mathrm{L}$, et al. Melatonin attenuates titanium particle-induced osteolysis via activation of $\mathrm{Wnt} / \beta$-catenin signaling pathway. Acta Biomater. 2017;51:513-525. doi:10.1016/j. actbio.2017.01.034

71. Wang J, Tao Y, Ping Z, et al. Icariin attenuates titanium-particle inhibition of bone formation by activating the Wnt/ $\beta$-catenin signaling pathway in vivo and in vitro. Sci Rep. 2016;6(1):1-10. doi:10.1038/s41598-016-0001-8

72. Qu R, Chen X, Yuan Y, et al. Ghrelin fights against titanium particle-induced inflammatory osteolysis through activation of $\beta$ catenin signaling pathway. Inflammation. 2019;42(5):1652-1665. doi:10.1007/s10753-019-01026-w

73. Zhang W, Lu X, Yuan Z, et al. Establishing an osteoimmunomodulatory coating loaded with aspirin on the surface of titanium primed with phase-transited lysozyme. Int $J$ Nanomedicine. 2019;14:977. doi:10.2147/IJN.S190766

74. Ko W-K, Kim SJ, Heo DN, et al. Double layers of gold nanoparticles immobilized titanium implants improve the osseointegration in rabbit models. Nanomedicine. 2020;24:102129. doi:10. 1016/j.nano.2019.102129

75. Chen Q, Wang N, Zhu M, et al. TiO2 nanoparticles cause mitochondrial dysfunction, activate inflammatory responses, and attenuate phagocytosis in macrophages: a proteomic and metabolomic insight. Redox Biol. 2018;15:266-276. doi:10.1016/j.redox.2017.12.011

76. Huang C, Sun M, Yang Y, et al. Titanium dioxide nanoparticles prime a specific activation state of macrophages. Nanotoxicology. 2017;11(6):737-750. doi:10.1080/17435390.2017.1349202

77. Zhou D, Han S, Yan T, et al. Toxicity of titanium dioxide nanoparticles induced by reactive oxygen species. Reactive Oxygen Species. 2019;8(23):267-275-267-275.

78. Dhupal M, Oh J-M, Tripathy DR, Kim S-K, Koh SB, Park K-S. Immunotoxicity of titanium dioxide nanoparticles via simultaneous induction of apoptosis and multiple toll-like receptors signaling through ROS-dependent SAPK/JNK and p38 MAPK activation. Int J Nanomedicine. 2018;13:6735. doi:10.2147/IJN.S176087

79. Baron L, Gombault A, Fanny M, et al. The NLRP3 inflammasome is activated by nanoparticles through ATP, ADP and adenosine. Cell Death Dis. 2015;6(2):e1629. doi:10.1038/cddis.2014.576

80. Morishige T, Yoshioka Y, Tanabe A, et al. Titanium dioxide induces different levels of IL-1 $\beta$ production dependent on its particle characteristics through caspase- 1 activation mediated by reactive oxygen species and cathepsin B. Biochem Biophys Res Commun. 2010;392(2):160-165. doi:10.1016/j.bbrc.2009.12.178

81. Yu Q, Wang H, Peng Q, Li Y, Liu Z, Li M. Different toxicity of anatase and rutile TiO2 nanoparticles on macrophages: involvement of difference in affinity to proteins and phospholipids. J Hazard Mater. 2017;335:125-134. doi:10.1016/j.jhazmat.2017.04.026

82. Hou Y, Cai K, Li J, et al. Effects of titanium nanoparticles on adhesion, migration, proliferation, and differentiation of mesenchymal stem cells. Int J Nanomedicine. 2013;8:3619. doi:10.2147/IJN.S37465

83. Ribeiro A, Gemini-Piperni S, Travassos R, et al. Trojan-like internalization of anatase titanium dioxide nanoparticles by human osteoblast cells. Sci Rep. 2016;6(1):23615. doi:10.1038/ srep 23615
84. Ibrahim M, Schoelermann J, Mustafa K, Cimpan MR. TiO2 nanoparticles disrupt cell adhesion and the architecture of cytoskeletal networks of human osteoblast-like cells in a size dependent manner. J Biomed Mater Res A. 2018;106(10):2582-2593. doi:10.1002/jbm.a.36448

85. Niska K, Pyszka K, Tukaj C, Wozniak M, Radomski MW, Inkielewicz-Stepniak I. Titanium dioxide nanoparticles enhance production of superoxide anion and alter the antioxidant system in human osteoblast cells. Int J Nanomedicine. 2015;10:1095.

86. Cai K, Hou Y, Hu Y, et al. Correlation of the cytotoxicity of TiO2 nanoparticles with different particle sizes on a sub-200-nm scale. Small. 2011;7(21):3026-3031. doi:10.1002/smll.201101170

87. Bernier M-C, El Kirat K, Besse M, Morandat S, Vayssade M. Preosteoblasts and fibroblasts respond differently to anatase titanium dioxide nanoparticles: a cytotoxicity and inflammation study. Colloids Surf B Biointerfaces. 2012;90:68-74. doi:10.10 16/j.colsurfb.2011.09.044

88. Zhang Y, Yu W, Jiang X, Lv K, Sun S, Zhang F. Analysis of the cytotoxicity of differentially sized titanium dioxide nanoparticles in murine MC3T3-E1 preosteoblasts. J Mater Sci Mater Med. 2011;22(8):1933-1945. doi:10.1007/s10856-011-4375-7

89. Souza W, Piperni S, Laviola P, et al. The two faces of titanium dioxide nanoparticles bio-camouflage in 3D bone spheroids. Sci Rep. 2019;9(1):9309. doi:10.1038/s41598-019-45797-6

90. Hughes LD, Chamberlain K, Sloan A, Choudry Q. Metal-on-metal hip arthroplasty-development and demise. Int J Orthopaed. 2018;5 (5):961-967. doi:10.17554/j.issn.2311-5106.2018.05.283

91. Liao Y, Hoffman E, Wimmer M, Fischer A, Jacobs J, Marks L. CoCrMo metal-on-metal hip replacements. Phys Chem Chem Phys. 2013;15(3):746-756. doi:10.1039/C2CP42968C

92. Jiang H, Liu F, Yang H, Li Y. Effects of cobalt nanoparticles on human T cells in vitro. Biol Trace Elem Res. 2012;146(1):23-29. doi:10.1007/s12011-011-9221-8

93. Doorn PF, Campbell PA, Worrall J, Benya PD, McKellop HA, Amstutz HC. Metal wear particle characterization from metal on metal total hip replacements: transmission electron microscopy study of periprosthetic tissues and isolated particles. J Biomed Mater Res. 1998;42(1):103-111. doi:10.1002/(SICI)1097-4636(199810)42:1<103::AID-JBM13>3.0.CO;2-M

94. Madl AK, Liong M, Kovochich M, Finley BL, Paustenbach DJ, Oberdörster G. Toxicology of wear particles of cobalt-chromium alloy metal-on-metal hip implants Part I: physicochemical properties in patient and simulator studies. Nanomedicine. 2015;11 (5):1201-1215. doi:10.1016/j.nano.2014.12.005

95. Xia Z, Ricciardi BF, Liu Z, et al. Nano-analyses of wear particles from metal-on-metal and non-metal-on-metal dual modular neck hip arthroplasty. Nanomedicine. 2017;13(3):1205-1217. doi:10.1016/j. nano.2016.11.003

96. Rakow A, Schoon J, Dienelt A, et al. Influence of particulate and dissociated metal-on-metal hip endoprosthesis wear on mesenchymal stromal cells in vivo and in vitro. Biomaterials. 2016;98:31-40. doi:10.1016/j.biomaterials.2016.04.023

97. Scharf B, Clement CC, Zolla V, et al. Molecular analysis of chromium and cobalt-related toxicity. Sci Rep. 2014;4(1):5729. doi:10.1038/srep05729

98. Wan R, Mo Y, Zhang Z, Jiang M, Tang S, Zhang Q. Cobalt nanoparticles induce lung injury, DNA damage and mutations in mice. Part Fibre Toxicol. 2017;14(1):38. doi:10.1186/s12989017-0219-z

99. Sisler JD, Li R, McKinney W, et al. Differential pulmonary effects of $\mathrm{CoO}$ and $\mathrm{La} 2 \mathrm{O} 3$ metal oxide nanoparticle responses during aerosolized inhalation in mice. Part Fibre Toxicol. 2015;13(1):42. doi:10.1186/s12989-016-0155-3

100. Kwon Y-M, Xia Z, Glyn-Jones S, Beard D, Gill HS, Murray DW. Dose-dependent cytotoxicity of clinically relevant cobalt nanoparticles and ions on macrophages in vitro. Biomed Mater. 2009;4 (2):025018. doi:10.1088/1748-6041/4/2/025018 
101. Liu Y, Ye J, Han Q, Tao R, Liu F, Wang W. Toxicity and bioactivity of cobalt nanoparticles on the monocytes. Orthop Surg. 2015;7(2):168-173. doi:10.1111/os.12180

102. Wang S, Liu F, Zeng Z, Yang H, Jiang H. The protective effect of bafilomycin A1 against cobalt nanoparticle-induced cytotoxicity and aseptic inflammation in macrophages in vitro. Biol Trace Elem Res. 2016;169(1):94-105. doi:10.1007/s12011-015-0381-9

103. Nyga A, Hart A, Tetley TD. Importance of the HIF pathway in cobalt nanoparticle-induced cytotoxicity and inflammation in human macrophages. Nanotoxicology. 2015;9(7):905-917. doi: 10.3109/17435390.2014.991430

104. Xu J, Yang J, Nyga A, et al. Cobalt (II) ions and nanoparticles induce macrophage retention by ROS-mediated down-regulation of RhoA expression. Acta Biomater. 2018;72:434-446. doi:10. 1016/j.actbio.2018.03.054

105. Han Q, Liu F. Low doses of Co nanoparticles induce death and regulate osteogenic differentiation in MG-63 cells. Mol Med Rep. 2017;16(5):7591-7596. doi:10.3892/mmr.2017.7512

106. Shah KM, Wilkinson JM, Gartland A. Cobalt and chromium exposure affects osteoblast function and impairs the mineralization of prosthesis surfaces in vitro. J Orthopaed Res. 2015;33 (11):1663-1670. doi:10.1002/jor.22932

107. Wauthle R, Van Der Stok J, Yavari SA, et al. Additively manufactured porous tantalum implants. Acta Biomater. 2015;14:217-225. doi:10.1016/j.actbio.2014.12.003

108. Stiehler M, Lind M, Mygind T, et al. Morphology, proliferation, and osteogenic differentiation of mesenchymal stem cells cultured on titanium, tantalum, and chromium surfaces. $J$ Biomed Mater Res Part A. 2008;86(2):448-458. doi:10.1002/jbm.a.31602

109. Balla VK, Bodhak S, Bose S, Bandyopadhyay A. Porous tantalum structures for bone implants: fabrication, mechanical and in vitro biological properties. Acta Biomater. 2010;6(8):3349-3359. doi:10.1016/j.actbio.2010.01.046

110. Lu M, Zhuang X, Tang K, et al. Intrinsic surface effects of tantalum and titanium on integrin $\alpha 5 \beta 1 /$ ERK1/2 pathway-mediated osteogenic differentiation in rat bone mesenchymal stromal cells. Cell Phys Biochem. 2018;51(2):589-609. doi:10.1159/000495280

111. Babis GC, Stavropoulos NA, Sasalos G, Ochsenkuehn-Petropoulou M, Megas P. Metallosis and elevated serum levels of tantalum following failed revision hip arthroplasty - a case report. Acta Orthop 2014;85(6):677-680. doi:10.3109/17453674.2014.950816

112. Schoon J, Geißler S, Traeger J, et al. Multi-elemental nanoparticle exposure after tantalum component failure in hip arthroplasty: in-depth analysis of a single case. Nanomedicine. 2017;13 (8):2415-2423. doi:10.1016/j.nano.2017.08.004

113. An R, Fan PP, Zhou MJ, et al. Nanolamellar tantalum interfaces in the osteoblast adhesion. Langmuir. 2019;35(7):2480-2489. doi:10.1021/acs.langmuir.8b02796

114. Wei X, Liu B, Liu G, et al. Mesenchymal stem cell-loaded porous tantalum integrated with biomimetic 3D collagen-based scaffold to repair large osteochondral defects in goats. Stem Cell Res Ther. 2019;10(1):72. doi:10.1186/s13287-019-1176-2

115. Huo WT, Zhao LZ, Yu S, Yu ZT, Zhang PX, Zhang YS. Significantly enhanced osteoblast response to nano-grained pure tantalum. Sci Rep. 2017;7(1):40868. doi:10.1038/srep40868

116. Shi L-Y, Wang A, Zang F-Z, Wang J-X, Pan X-W, Chen H-J. Tantalum-coated pedicle screws enhance implant integration. Colloids Surf B Biointerfaces. 2017;160:22-32. doi:10.1016/j. colsurfb.2017.08.059

117. Kang C, Wei L, Song B, et al. Involvement of autophagy in tantalum nanoparticle-induced osteoblast proliferation. Int J Nanomedicine. 2017;12:4323. doi:10.2147/IJN.S136281

118. Wang P, Qiao P, Xing H, Zhang R, Lingling E, Liu H. Cytotoxicity, oxidative stress, and autophagy effects of tantalum nanoparticles on mc3t3-e1 mouse osteoblasts. J Nanosci Nanotechnol. 2020;20 (3):1417-1424. doi:10.1166/jnn.2020.17158
119. Schubert D, Dargusch R, Raitano J, Chan S-W. Cerium and yttrium oxide nanoparticles are neuroprotective. Biochem Biophys Res Commun. 2006;342(1):86-91. doi:10.1016/j.bbrc.20 06.01.129

120. Marquardt C, Fritsch-Decker S, Al-Rawi M, Diabaté S, Weiss C. Autophagy induced by silica nanoparticles protects RAW264. 7 macrophages from cell death. Toxicology. 2017;379:40-47. doi:10.1016/j.tox.2017.01.019

121. Zhang X, Yin H, Li Z, Zhang T, Yang Z. Nano-TiO 2 induces autophagy to protect against cell death through antioxidative mechanism in podocytes. Cell Biol Toxicol. 2016;32(6): 513-527. doi:10.1007/s10565-016-9352-y

122. Wang Z, Liu N, Liu K, et al. Autophagy mediated CoCrMo particle-induced peri-implant osteolysis by promoting osteoblast apoptosis. Autophagy. 2015;11(12):2358-2369. doi:10.1080/155 48627.2015.1106779

123. Yang L, Meng H, Yang M. Autophagy protects osteoblasts from advanced glycation end products-induced apoptosis through intracellular reactive oxygen species. $J$ Mol Endocrinol. 2016;56 (4):291-300. doi:10.1530/JME-15-0267

124. Zichner LP, Willert H-G. Comparison of alumina-polyethylene and metal-polyethylene in clinical trials. Clin Orthop Relat Res. 1992;282:86-94.

125. D'Antonio JA, Sutton K. Ceramic materials as bearing surfaces for total hip arthroplasty. JAAOS. 2009;17(2):63-68. doi:10.5435/ 00124635-200902000-00002

126. Li RWK, Chow TW, Matinlinna JP. Ceramic dental biomaterials and CAD/CAM technology: state of the art. J Prosthodont Res. 2014;58(4):208-216. doi:10.1016/j.jpor.2014.07.003

127. Kurtz SM, Kocagöz S, Arnholt C, Huet R, Ueno M, Walter WL. Advances in zirconia toughened alumina biomaterials for total joint replacement. J Mech Behav Biomed Mater. 2014;31:1 07-116. doi:10.1016/j.jmbbm.2013.03.022

128. Rambani R, Kepecs DM, Mäkinen TJ, Safir OA, Gross AE, Kuzyk PR. Revision total hip arthroplasty for fractured ceramic bearings: a review of best practices for revision cases. $J$ Arthroplasty. 2017;32(6):1959-1964. doi:10.1016/j.arth.2016.12.050

129. Xiang S, Zhao Y, Li Z, Feng B, Weng X. Clinical outcomes of ceramic femoral prosthesis in total knee arthroplasty: a systematic review. J Orthop Surg Res. 2019;14(1):57. doi:10.1186/s13018-019-1090-4

130. Heyse TJ, Elpers ME, Nawabi DH, Wright TM, Haas SB. Oxidized zirconium versus cobalt-chromium in TKA: profilometry of retrieved femoral components. Clin Orthopaed Related Res. 2014;472(1):277-283. doi:10.1007/s11999-013-3078-4

131. Malahias M-A, Atrey A, Gu A, Chytas D, Nikolaou VS, Waddell JP. Is oxidized zirconium femoral head superior to other bearing types in total hip arthroplasty? A systematic review and meta-analysis. $J$ Arthroplasty. 2019;34(8):1844-1852. doi:10.1016/j.arth.2019.03.072

132. Zou AH, Novikov D, Feng JE, Anoushiravani AA, Schwarzkopf R, Vigdorchik JM. Liner dissociation leading to catastrophic failure of an Oxinium femoral head. Arthroplasty Today. 2019;5(1):21-25. doi:10.1016/j.artd.2018.09.009

133. Gillani R, Ercan B, Qiao A, Webster TJ. Nanofunctionalized zirconia and barium sulfate particles as bone cement additives. Int $j$ nanomed. 2010;5(1):1-11.

134. Dusad A, Chakkalakal DA, Namavar F, et al. Titanium implant with nanostructured zirconia surface promotes maturation of peri-implant bone in osseointegration. Proc Inst Mech Eng H. 2013;227(5):510-522. doi:10.1177/ 0954411913479300

135. Schunck A, Kronz A, Fischer C, Buchhorn GH. Release of zirconia nanoparticles at the metal stem-bone cement interface in implant loosening of total hip replacements. Acta Biomater. 2016;31:412-424. doi:10.1016/j.actbio.2015.11.044 
136. Silge A, Bocklitz T, Ossig R, Schnekenburger J, Rösch P, Popp J. The interaction of an amino-modified $\mathrm{ZrO} 2$ nanomaterial with macrophages - an in situ investigation by Raman microspectroscopy. Anal Bioanal Chem. 2016;408(21):5935-5943. doi:10. 1007/s00216-016-9710-x

137. Vennemann A, Alessandrini F, Wiemann M. Differential effects of surface-functionalized zirconium oxide nanoparticles on alveolar macrophages, rat lung, and a mouse allergy model. Nanomaterials. 2017;7(9):280. doi:10.3390/nano7090280

138. Pasold J, Markhoff J, Tillmann J, Krogull M, Pisowocki P, Bader R. Direct influence of titanium and zirconia particles on the morphology and functionality of mature human osteoclasts. $J$ Biomed Mater Res A. 2017;105(9):2608-2615. doi:10.1002/jbm.a.36114

139. Zhang Y, Zheng Y, Qin L. A comprehensive biological evaluation of ceramic nanoparticles as wear debris. Nanomedicine. 2011;7 (6):975-982. doi:10.1016/j.nano.2011.04.005

140. Ye M, Shi B. Zirconia nanoparticles-induced toxic effects in osteoblast-like 3T3-E1 cells. Nanoscale Res Lett. 2018;13 (1):353. doi:10.1186/s11671-018-2747-3

141. Dalal A, Pawar V, McAllister K, Weaver C, Hallab NJ. Orthopedic implant cobalt-alloy particles produce greater toxicity and inflammatory cytokines than titanium alloy and zirconium alloy-based particles in vitro, in human osteoblasts, fibroblasts, and macrophages. $J$ Biomed Mater Res A. 2012;100 (8):2147-2158. doi:10.1002/jbm.a.34122

142. Rutherford D, Exarhos S, Xu C, et al. Synthesis, characterization, and cytocompatibility of yttria stabilized zirconia nanopowders for creating a window to the brain. $J$ Biomed Mater Res B Appl Biomater. 2019;108:925.

143. Wang ML, Tuli R, Manner PA, Sharkey PF, Hall DJ, Tuan RS. Direct and indirect induction of apoptosis in human mesenchymal stem cells in response to titanium particles. J Orthopaed Res. 2003;21(4):697-707. doi:10.10 16/S0736-0266(02)00241-3

144. Kummer FJ, Stuchin SA, Frankel VH. Analysis of removed autophor ceramic-on-ceramic components. $J$ Arthroplasty. 1990;5(1):29-33. doi:10.1016/S0883-5403(06)80006-9

145. Henssge E, Bos I, Willmann G. Al $2 \mathrm{O} 3$ against $\mathrm{Al} 2 \mathrm{O} 3$ combination in hip endoprostheses. Histologic investigations with semiquantitative grading of revision and autopsy cases and abrasion measures. J Mater Sci Mater Med. 1994;5(9-10):657-661.

146. Hatton A, Nevelos J, Nevelos A, Banks R, Fisher J, Ingham E. Alumina-alumina artificial hip joints. Part I: a histological analysis and characterisation of wear debris by laser capture microdissection of tissues retrieved at revision. Biomaterials. 2002;23(16):3429-3440. doi:10.1016/S0142-9612(02)00047-9
147. Kim Y-S, Chung Y-H, Seo D-S, Choi H-S, Lim C-H. Twentyeight-day repeated inhalation toxicity study of aluminum oxide nanoparticles in male Sprague-Dawley rats. Toxicol Res. 2018;34 (4):343. doi:10.5487/TR.2018.34.3.343

148. Hashimoto M, Sasaki JI, Imazato S. Investigation of the cytotoxicity of aluminum oxide nanoparticles and nanowires and their localization in L 929 fibroblasts and RAW 264 macrophages. $J$ Biomed Mater Res B Appl Biomater. 2016;104(2):241-252. doi:10.1002/jbm.b.33377

149. Mestres G, Espanol M, Xia W, Tenje M, Ott M. Evaluation of biocompatibility and release of reactive oxygen species of aluminum oxide-coated materials. ACS Omega. 2016;1(4):706-713. doi:10.1021/acsomega.6b00198

150. Flaherty NL, Chandrasekaran A, Peña M, et al. Comparative analysis of redox and inflammatory properties of pristine nanomaterials and commonly used semiconductor manufacturing nano-abrasives. Toxicol Lett. 2015;239(3):205-215. doi:10.1016/j.toxlet.2015.09.025

151. Dandley EC, Taylor AJ, Duke KS, et al. Atomic layer deposition coating of carbon nanotubes with zinc oxide causes acute phase immune responses in human monocytes in vitro and in mice after pulmonary exposure. Part Fibre Toxicol. 2015;13(1):29. doi:10. 1186/s12989-016-0141-9

152. Braydich-Stolle LK, Speshock JL, Castle A, Smith M, Murdock RC, Hussain SM. Nanosized aluminum altered immune function. $A C S$ Nano. 2010;4(7):3661-3670. doi:10.1021/nn9016789

153. Di Virgilio AL, Reigosa M, de Mele MF. Response of UMR 106 cells exposed to titanium oxide and aluminum oxide nanoparticles. J Biomed Mater Res A. 2010;92(1):80-86. doi:10.1002/jbm.a.32339

154. Periasamy VS, Athinarayanan J, Alshatwi AA. Aluminum oxide nanoparticles alter cell cycle progression through CCND1 and EGR1 gene expression in human mesenchymal stem cells. Biotechnol Appl Biochem. 2016;63(3):320-327. doi:10.1002/bab.1368

155. Wang $\mathrm{C}$, $\mathrm{Li} \mathrm{Z}$, Wang $\mathrm{H}$, et al. Nano-sized Al 2 O 3 particle-induced autophagy reduces osteolysis in aseptic loosening of total hip arthroplasty by negative feedback regulation of RANKL expression in fibroblasts. Cell Death Dis. 2018;9 (8):1-15. doi:10.1038/s41419-017-0012-9

156. Zhang $\mathrm{Z}, \mathrm{Fu} \mathrm{X}, \mathrm{Xu} \mathrm{L}$, et al. Nanosized alumina particle and proteasome inhibitor bortezomib prevented inflammation and osteolysis induced by titanium particle via autophagy and NF-kB Signaling. Sci Rep. 2020;10 (1):1-12. doi:10.1038/s41598-019-56847-4

157. Bitounis D, Pourchez J, Forest V, Boudard D, Cottier M, Klein J-P. Detection and analysis of nanoparticles in patients: a critical review of the status quo of clinical nanotoxicology. Biomaterials. 2016;76:302-312. doi:10.1016/j.biomaterials.2015.10.061
International Journal of Nanomedicine

\section{Publish your work in this journal}

The International Journal of Nanomedicine is an international, peerreviewed journal focusing on the application of nanotechnology in diagnostics, therapeutics, and drug delivery systems throughout the biomedical field. This journal is indexed on PubMed Central, MedLine, CAS, SciSearch ${ }^{\mathbb{R}}$, Current Contents ${ }^{\mathbb{R}} /$ Clinical Medicine, $^{2}$
Journal Citation Reports/Science Edition, EMBase, Scopus and the Elsevier Bibliographic databases. The manuscript management system is completely online and includes a very quick and fair peer-review system, which is all easy to use. Visit http://www.dovepress.com/ testimonials.php to read real quotes from published authors. 